\title{
Exploring chromium (VI) dioxodihalides chemistry: Is density functional theory the most suitable tool?
}

\author{
M. Torrent \\ Institute of Computational Chemistry and Department of Chemistry, University of Girona, 17071 Girona, \\ Catalonia, Spain \\ P. Gili \\ Department of Inorganic Chemistry, University of La Laguna, 38204 La Laguna, Tenerife, Canary Islands, \\ Spain \\ M. Duran a) and M. Solà \\ Institute of Computational Chemistry and Department of Chemistry, University of Girona, 17071 Girona, \\ Catalonia, Spain
}

(Received 5 February 1996; accepted 13 March 1996)

\begin{abstract}
A comparative systematic study of the $\mathrm{CrO}_{2} \mathrm{~F}_{2}$ compound has been performed using different conventional $a b$ initio methodologies and density functional procedures. Two points have been analyzed: first, the accuracy of results yielded by each method under study, and second, the computational cost required to reach such results. Weighing up both aspects, density functional theory has been found to be more appropriate than the Hartree-Fock (HF) and the analyzed post-HF methods. Hence, the structural characterization and spectroscopic elucidation of the full $\mathrm{CrO}_{2} \mathrm{X}_{2}$ series $(\mathrm{X}=\mathrm{F}, \mathrm{Cl}, \mathrm{Br}, \mathrm{I})$ has been done at this level of theory. Emphasis has been given to the unknown $\mathrm{CrO}_{2} \mathrm{I}_{2}$ species, and specially to the UV/visible spectra of all four compounds. Furthermore, a topological analysis in terms of charge density distributions has revealed why the valence shell electron pair repulsion model fails in predicting the molecular shape of such $\mathrm{CrO}_{2} \mathrm{X}_{2}$ complexes. (C) 1996 American Institute of Physics. [S0021-9606(96)01323-2]
\end{abstract}

\section{INTRODUCTION}

Chromium (VI) dioxodihalides form a class of versatile oxidizing agents able to deliver oxygen atoms to a great deal of organic groups. These oxotransition metal complexes of chromium in higher oxidation states have been taken as functional chemical models for cytochrome P-450. ${ }^{1}$ In particular, the electronic structure of chromium (VI) dioxodichloride has been studied in order to elucidate how this kind of systems can mimic mixed-function oxygenases of biological importance and in what fashion the oxygen ligands participate in electrophilic reactions. ${ }^{2}$ Results suggested that the reactivity of $\mathrm{CrO}_{2} \mathrm{Cl}_{2}$ involve charge-transfer interactions, concluding that a consistent description of the electrophilic oxygen is obtained based on covalent rather than electrostatic interactions with the substrate. Very recently, Ziegler and $\mathrm{Li}^{3}$ studied theoretically the methanol oxidation by $\mathrm{CrO}_{2} \mathrm{Cl}_{2}$ and the reaction enthalpies involved in the activation of $\mathrm{C}-\mathrm{H}$ and $\mathrm{O}-\mathrm{H}$ bonds. They suggested that $\mathrm{O}-\mathrm{H}$ addition to the $\mathrm{Cr}-\mathrm{O}$ bond is an important step of such catalytic process. While $\mathrm{CrO}_{2} \mathrm{Cl}_{2}$ has attracted most interest of both experimental and theoretical chemists, ${ }^{4-8}$ the other dioxodihalides of the same chromium family have received much less attention. Unlike $\mathrm{CrO}_{2} \mathrm{~F}_{2}$ and $\mathrm{CrO}_{2} \mathrm{Cl}_{2}$ the third member of this series is difficult to prepare: ${ }^{9}$ even below room temperature, $\mathrm{CrO}_{2} \mathrm{Br}_{2}$ is thermally unstable, most of its physico-chemical properties being still unknown. However, it was found to exist as a

\footnotetext{
${ }^{\text {a) }}$ To whom all correspondence should be addressed (electronic mail: quel@stark.udg.es, FAX: +34.72.41.83.61, phone: +34.72.41.83.64).
}

monomeric species, as revealed by its molecular weight in $\mathrm{CCl}_{4} \cdot{ }^{10}$ Finally, $\mathrm{CrO}_{2} \mathrm{I}_{2}$ has not been synthesized yet.

The theoretical characterization of inorganic compounds is not at all an easy task. ${ }^{11-21}$ Thus, whereas the application of mechano-quantum methodology on organic systems has reached a stage not only interpretative but also predictive, ${ }^{22}$ transition-metal compounds are more difficult to be described due to four main reasons. First, the quantity of atoms taking part cover practically the whole periodic table. Second, the variety of bonds which are made cannot necessarily be considered as covalent bonds like in organic compounds. Third, for transition-metal systems there is usually more than one possible hybridization scheme. Finally, bonds between metal and nonmetal atoms are difficult to be theoretically treated, due to the many orbitals of the metal having an active role. In general, the energy of these systems suffers from nonsystematic errors, and much more accurate calculations than for organic compounds are required. As far as chromium (VI) dioxodihalides are concerned, apart from the aforementioned studies on $\mathrm{CrO}_{2} \mathrm{Cl}_{2}$ compound, only a theoretical description of the chromium (VI) dioxodifluoride has been given by Deeth, ${ }^{23}$ including optimized geometries and vibrational frequencies. To our knowledge, calculations on the two heavier members of the family $(\mathrm{X}=\mathrm{Br}, \mathrm{I})$ are still missing.

In recent years, density functional theory $(\mathrm{DFT})^{24-28}$ applied to chemistry has emerged as a promising method, in part because of the inclusion of electron correlation effects at a low computational cost. Although several studies have proven approximate DFT to be a powerful computational 
tool in determining the structures and energetics of transition-metal complexes, ${ }^{29,30}$ little work exists for UV/vis spectra calculations. Furthermore, while there is a growing literature $^{31-39}$ on systematic comparisons of DFT theories with experiment and also with Hartee-Fock (HF) and Møller-Plesset (MP2) treatments, few comparative studies have taken other post-HF methodologies (CISD, MCSCF) into account as well, and, when these have been included, only small molecules have been discussed. ${ }^{39-41}$ Regarding heavier systems, perhaps the most comprehensive work is that of Sosa et al. ${ }^{42}$ who have studied structures and frequencies for a number of first and second-row transition-metal complexes at the local density approximation (LDA) level. In this approach, HF and LDA results were compared, the latter being in better agreement with experiment. However, similar works on transition metals comparing HF, post-HF, and nonlocal DFT methods are still lacking.

Despite several calculations for $\mathrm{CrO}_{2} \mathrm{~F}_{2}$ and $\mathrm{CrO}_{2} \mathrm{Cl}_{2}$ complexes, ${ }^{23,42}$ no comparative studies exist for the complete $\mathrm{CrO}_{2} \mathrm{X}_{2}$ series $(\mathrm{X}=\mathrm{F}, \mathrm{Cl}, \mathrm{Br}, \mathrm{I})$. Thus, the main aim of the present paper is to assess the geometrical, vibrational, and electronic properties of the family of species $\mathrm{CrO}_{2} \mathrm{X}_{2}$. In particular, theoretical studies on the electronic spectra of these compounds are reported for the first time and compared to experimental UV/visible spectra when possible. Special emphasis is placed on $\mathrm{CrO}_{2} \mathrm{Br}_{2}$ and $\mathrm{CrO}_{2} \mathrm{I}_{2}$ species.

Another purpose of this article consists of searching the optimum theoretical and computational conditions to perform such analyses. Thus, before pursuing our main goal, we have carried out a systematic study on the $\mathrm{CrO}_{2} \mathrm{~F}_{2}$ compound in order to find the most suitable methodology to be employed, calculating several properties at different levels of theory, and further comparing not only the quality of results but also the computational effort required for each tested methodology. With regards to DFT calculations, several functionals and packages have been used. An interesting goal pursued when comparing different DFT methodologies is to discover the disadvantages and benefits of different available density functionals, in this particular case, for transitionmetal systems. These kind of studies can also help to understand how the calculated properties can be improved with the inclusion of nonlocal corrections.

Finally, our studies are also prompted by the continued interest in a comprehension of why the valence shell electron pair repulsion (VSEPR) predictions for transition-metal complexes fail in some cases. ${ }^{43}$ In the present case, a $\angle \mathrm{OCrO}$ bond angle is expected to be larger than a $\angle \mathrm{XCrX}$ angle ( $\mathrm{X}=$ halogen), according to the VSEPR principle stating that double formal bonds require a greater proportion of the coordination sphere around a central atom than single bonds do. Interestingly, our DFT results reproduce the observed $\angle \mathrm{OCrO}<\angle \mathrm{XCrX}$ order, whereas both the VSEPR model and some HF calculations are in contradiction to experimental evidence.

\section{COMPUTATIONAL DETAILS}

$\mathrm{HF}$ and post-HF $a b$ initio calculations have been carried out with the system of programs GAUSSIAN $92,{ }^{44}$ the only exception being complete active space self-consistent field (CASSCF) calculations, which have been performed by means of the GAMESS program. ${ }^{45}$

DFT calculations have been done with the programs DMol $^{46}{ }^{\mathrm{ADF}}{ }^{47}$ and GAUSSIAN 92. Both functionals of the density (local) and the density gradient (nonlocal) have been used. On the first category, calculations have been performed within $\mathrm{LDA}^{48}$ in the parametrization of Vosko, Wilk, and Nusair (VWN) ${ }^{49}$ or, alternatively, in the Hedin-Lundqvist/ Janak-Morruzi-Williams (JMW) ${ }^{50}$ local correlation functional. In the more sophisticated nonlocal density approximation (NLDA), pure Becke's (B) ${ }^{51}$ or hybrid Becke's 3 parameters' (B3P) ${ }^{52}$ nonlocal correction for the exchange were added, as well as Lee-Yang-Parr (LYP) ${ }^{53}$ or Perdew's $(\mathrm{P})^{54}$ inhomogeneous gradient corrections for correlation. An accurate integration grid has been chosen everywhere.

As regards to the particular features of each program, DMol employs numerical functions for the atomic basis sets, and the various integrals arising from the expression for the energy equation are then evaluated over a grid. The DMol calculations have been done with a double numerical basis set augmented by polarization functions (DNP). For comparison with traditional molecular orbital methods, DNP can be considered in terms of size as a polarized double- $\zeta$ basis set. However, this basis set is of significantly higher quality than a normal molecular orbital double- $\zeta$ basis set, because exact numerical solutions for the atom are used. ${ }^{46}$ Harmonic vibrational frequencies have been evaluated by finite differences of analytic gradients.

The Gaussian basis sets employed in our GAUSSIAN 92 calculations have taken in a wide range from pseudopotential basis sets up to double or triple- $\zeta$ valence plus polarization all-electron basis sets. ${ }^{55-59}$ For the sake of clarity, we have labeled the Gaussian basis sets used in the first part of this paper as shown in Table I. Second derivatives of the energy have been computed analytically.

In the ADF program, the implementation is centered around an optimized numerical integration scheme, extensive use of point group symmetry being made. Basis functions are Slater-type orbitals (STOs). The Coulomb potential is evaluated through a fitting of the charge density with Slater-type exponential functions centered on the atoms (fit functions). ${ }^{60}$ Thus, a triple- $\zeta$ basis set has been used for the $3 s, 3 p, 3 d$, $4 s$, and $4 p$ orbitals of chromium. For fluorine $(2 s, 2 p)$, chlorine $(3 s, 3 p)$, bromine $(3 d, 4 s, 4 p)$, and oxygen $(2 s, 2 p)$, double- $\zeta$ basis sets augmented by an extra polarization function have been employed. ${ }^{61} \mathrm{~A}$ similar basis set for iodine was not available, so a triple- $\zeta$ STO basis extended with a polarization function has been used instead for this halogen. It is unlikely that the choice of a better basis set for iodine could affect the validity of results when comparing trends along the series. Electrons in inner shells have been treated within the frozen core approximation. ${ }^{62}$ Harmonic vibrational frequencies have been calculated by applying numerical differentiation to the energy gradients.

Spin-restricted calculations have been performed for the ground states and for the lower-lying excited states. The vertical excited-state energies have been estimated through the 
TABLE I. Basis sets used for calculations on $\mathrm{CrO}_{2} \mathrm{~F}_{2}$ using the GAUSSIAN 92 program.

\begin{tabular}{|c|c|c|c|}
\hline \multirow[b]{2}{*}{ Label } & \multicolumn{2}{|c|}{ Basis set description } & \multirow{2}{*}{$\begin{array}{l}\text { No. of basis } \\
\text { functions }\end{array}$} \\
\hline & $\operatorname{Metal}(\mathrm{Cr})$ & Ligands & \\
\hline A & $\operatorname{lanl} 1 \mathrm{mb}^{\mathrm{a}}$ & $\operatorname{lanl1} \mathrm{mb}^{\mathrm{a}}$ & 30 \\
\hline B & $\operatorname{lan} 11 \mathrm{dz}^{\mathrm{a}}$ & $\operatorname{lanl1} \mathrm{dz}^{\mathrm{a}}$ & 54 \\
\hline $\mathrm{C}$ & pseudopot. $^{\mathrm{b}}$ & $3-21 G^{c}$ & 60 \\
\hline $\mathrm{D}$ & pseudopot. $(d)^{\mathrm{b}, \mathrm{d}}$ & $3-21 \mathrm{G}(d)^{\mathrm{c}, \mathrm{e}}$ & 85 \\
\hline E & $3-21 G^{f}$ & $3-21 \mathrm{G}^{\mathrm{c}}$ & 79 \\
\hline $\mathrm{F}$ & $3-21 \mathrm{G}^{\mathrm{f}}$ & $3-21 \mathrm{G}(d)^{\mathrm{c}, \mathrm{e}}$ & 83 \\
\hline G & $3-21 \mathrm{G}(d)^{\mathrm{f}, \mathrm{d}}$ & $3-21 \mathrm{G}(d)^{\mathrm{c}, \mathrm{e}}$ & 88 \\
\hline $\mathrm{H}$ & $3-21 \mathrm{G}(f)^{\mathrm{f}, \mathrm{g}}$ & $3-21 \mathrm{G}(d)^{\mathrm{c}, \mathrm{e}}$ & 90 \\
\hline I & Wachters $^{\mathrm{h}}$ & $6-31 \mathrm{G}(d)^{\mathrm{i}, \mathrm{e}}$ & 86 \\
\hline $\mathrm{J}$ & Wachters $(311)^{\mathrm{h}}$ & $6-31 \mathrm{G}(d)^{\mathrm{i}, \mathrm{e}}$ & 91 \\
\hline K & Wachters $(f)^{\mathrm{h}, \mathrm{g}}$ & $6-31 \mathrm{G}(d)^{\mathrm{i}, \mathrm{e}}$ & 93 \\
\hline $\mathrm{L}$ & Wachters $(311)^{\mathrm{h}}$ & $6-311 \mathrm{G}(d)^{\mathrm{i}, \mathrm{e}}$ & 107 \\
\hline
\end{tabular}

${ }^{\mathrm{a}}$ Reference 55 .

${ }^{\mathrm{b}}$ Reference 55(c).

${ }^{\mathrm{c}}$ Reference 56.

${ }^{\mathrm{d}} \alpha d(\mathrm{Cr})=0.0972944$.

${ }^{\mathrm{e}} \alpha d(\mathrm{O})=0.8, \alpha d(\mathrm{~F})=0.8$.

${ }^{\mathrm{f}}$ Reference 57.

${ }^{\mathrm{g}} \alpha f(\mathrm{Cr})=1.0582$

${ }^{\text {h}}$ Reference 58.

${ }^{\mathrm{i}}$ Reference 59.

configuration interaction singles theory (CIS) ${ }^{63}$ for HF calculations, and through the sum method developed by Ziegler et al. ${ }^{29,64}$ for DFT calculations.

Electronic analyses of the Laplacian of the density and location of bond critical points (BCPs) through topological analyses have been done using the program ELECTRA ${ }^{65}$ developed in our laboratory.

\section{RESULTS AND DISCUSSION}

This section is divided in two subsections. It begins by considering a previous systematic study of the $\mathrm{CrO}_{2} \mathrm{~F}_{2}$ compound in order to elucidate which methodology must be used in terms of computational effort required and quality of results obtained. Once the optimum theoretical conditions are established in Sec. III A, we give place to the proper investigation of the full family of $\mathrm{CrO}_{2} \mathrm{X}_{2}$ compounds in Sec. III $\mathrm{B}$, which is actually the main objective of this paper.

\section{A. A systematic study of the $\mathrm{CrO}_{2} \mathrm{~F}_{2}$ complex}

Schematically, results are presented in the following order: First, calculated structural parameters, harmonic frequencies, and excitation energies are compared to available experimental data, the accuracy yielded by each methodology under study being also analyzed. Second, a comparison is made in terms of CPU time required for evaluating the test compound at different levels of theory. Finally, conclusions drawn from both previous points lead to a decision about the computationally most efficient choice.

\section{Molecular structures}

The $\mathrm{CrO}_{2} \mathrm{~F}_{2}$ molecule, which belongs to the $C_{2 v}$ point group, has the atoms located at roughly tetrahedral positions. Many investigations ${ }^{66,67}$ have revealed and confirmed a
TABLE II. Geometrical parameters for $\mathrm{CrO}_{2} \mathrm{~F}_{2}$ calculated at ab initio $\mathrm{HF}$ level. Bond distances in $\AA$ and angles in degrees.

\begin{tabular}{ccccc}
\hline \hline Basis & $r(\mathrm{Cr}-\mathrm{O})$ & $r(\mathrm{Cr}-\mathrm{F})$ & $\angle \mathrm{FCrF}$ & $\angle \mathrm{OCrO}$ \\
\hline $\mathrm{A}$ & 1.465 & 1.579 & 105.7 & 108.7 \\
$\mathrm{~B}$ & 1.413 & 1.745 & 109.5 & 106.9 \\
$\mathrm{C}$ & 1.526 & 1.656 & 111.1 & 107.5 \\
$\mathrm{D}$ & 1.506 & 1.641 & 111.4 & 107.4 \\
$\mathrm{E}$ & 1.494 & 1.676 & 109.9 & 108.2 \\
$\mathrm{~F}$ & 1.560 & 1.677 & 109.8 & 108.7 \\
$\mathrm{G}$ & 1.485 & 1.651 & 108.1 & 109.0 \\
$\mathrm{H}$ & 1.465 & 1.637 & 108.9 & 108.4 \\
$\mathrm{I}$ & 1.486 & 1.674 & 109.6 & 108.4 \\
$\mathrm{~J}$ & 1.490 & 1.674 & 109.3 & 108.5 \\
$\mathrm{~K}$ & 1.478 & 1.668 & 109.5 & 108.3 \\
$\mathrm{~L}$ & 1.481 & 1.688 & 109.5 & 108.2 \\
Expt. $^{\mathrm{a}}$ & 1.575 & 1.720 & 111.9 & 107.8 \\
\hline \hline
\end{tabular}

${ }^{\mathrm{a}}$ From Ref. 67

pseudotetrahedral $C_{2 v}$ structure for this molecule, which is not exclusive of $\mathrm{CrO}_{2} \mathrm{~F}_{2}$, but is also extensible to the full $\mathrm{CrO}_{2} \mathrm{X}_{2}$ series. Hence, only four geometrical parameters are needed to characterize the present compound. Table II gathers the observed geometrical parameters for $\mathrm{CrO}_{2} \mathrm{~F}_{2}$, along with those computed at the HF level. All calculated distances (which are not mean distances of the vibrational ground state, but equilibrium distances) are systematically shorter than the observed bond lengths. Most basis sets yield bond lengths with a deviation $\geqslant 0.05 \AA$ relative to experimental data. The fact that the rather poor basis $\mathrm{F}$ gives accidentally a low deviation of $0.015 \AA$ for $\mathrm{Cr}-\mathrm{O}$ and $0.043 \AA$ for $\mathrm{Cr}-\mathrm{F}$ is not so interesting (basis G gives already a $0.10 \AA$ deviation). It is important that the HF limit result is $\sim 0.10 \AA$ off.

Regarding bond angles, nearly all basis sets can reproduce the experimental relation $\angle \mathrm{FCrF}>\angle \mathrm{OCrO}$, the only exception being basis sets $\mathrm{A}$ and $\mathrm{G}$. However, it is surprising that the best description corresponds to basis sets C and D, which use pseudopotentials for Cr. Apart from these two basis sets, other all-electron basis sets underestimate the $\angle \mathrm{FCrF}$ angle by more than $2.0^{\circ}$, and overestimate the $\angle \mathrm{OCrO}$ angle. The comparison of results from different basis sets allows us to conclude with fair confidence that systematic underestimation of the $\mathrm{Cr}-\mathrm{O}$ and $\mathrm{Cr}-\mathrm{F}$ distances is due to intrinsic errors of the HF method and not to the use of unbalanced or too small basis sets. Due to computational limitations, subsequent calculations at post-HF level have been carried out through use of the medium-sized basis set G.

The effect of including electron correlation by means of post-HF methodologies can be seen from Table III. Metalligand distances are slightly improved at the MP2 level, but they are now larger than experimental values as a result of correlation effects being overestimated by the MP2 method. $^{41,68}$ Neither $\angle \mathrm{FCrF}$ nor $\angle \mathrm{OCrO}$ bond angles are properly described, the deviation being larger than that in Table II. Moreover, the quality of results provided by the CISD calculation only slightly overcomes the quality of HF results.

A more complex method has been used to improve the 
TABLE III. Geometrical parameters for $\mathrm{CrO}_{2} \mathrm{~F}_{2}$ calculated at post-HF level with basis set labeled G. Bond distances in $\AA$ and angles in degrees.

\begin{tabular}{ccccc}
\hline \hline Method & $r(\mathrm{Cr}-\mathrm{O})$ & $r(\mathrm{Cr}-\mathrm{F})$ & $\angle \mathrm{FCrF}$ & $\angle \mathrm{OCrO}$ \\
\hline MP2 & 1.667 & 1.762 & 119.2 & 104.4 \\
CISD & 1.512 & 1.666 & 109.5 & 108.3 \\
CASSCF $^{2}$ & 1.572 & 1.711 & 117.3 & 104.9 \\
Expt. $^{\mathrm{a}}$ & 1.575 & 1.720 & 111.9 & 107.8 \\
\hline \hline
\end{tabular}

${ }^{\mathrm{a}}$ From Ref. 67.

geometrical description of $\mathrm{CrO}_{2} \mathrm{~F}_{2}$. In particular, the CASSCF values reported in Table III correspond to a calculation with an 11-orbital active space [basically the six occupied $2 p$ atomic orbitals (AO) of the two oxygen atoms and five unoccupied $3 d \mathrm{AO}$ of $\mathrm{Cr}$ ] and 12 valence electrons, summing up a total of 15416 configurations. Such an active space yields an accurate description of bond lengths, the error lying below $0.01 \AA$. However, the computed bond angles remarkably deviate from the observed data, especially as regards to $\angle \mathrm{FCrF}$. This is probably due to the absence of the $2 p$ AO from fluorine ligands when accounting for the make-up of the active space. Such orbitals are more stabilized than the $2 p \mathrm{AO}$ of oxygen. To get a more balanced active space one should include the $2 p$ AO from $\mathrm{O}$ and $\mathrm{F}$; however, these orbitals cannot be included simultaneously unless a huge active space beyond 11 orbitals is considered, which goes well beyond our currently available computational resources.

An alternative way of considering electron correlation effects is given by the use of DFT. Table IV gathers the optimized geometries for each DFT method and program tested. All basis sets considered are of similar quality. There is a good agreement between observed and calculated geometries. Bond angles and lengths computed by means of the $\mathrm{ADF}$ and DMol programs are slightly better than those yielded by GAUSSIAN 92. This is probably due to the kind of basis sets employed. It must be remarked that for GAUSSIAN 92 we have not made use of basis sets especially developed and optimized for DFT calculations. Some time ago, it was found ${ }^{69}$ that the shape of valence orbitals for atoms such as $\mathrm{Cr}$ differ considerably between HF and LDA results. More recently, ${ }^{70}$ the use of LDA-optimized basis sets was recommended for the study of chemical energetics as well as geometries. However, HF-optimized basis sets are quite used in DFT calculations, partly because of the experience accumulated from HF calculations.

Chromium-ligand bond distances reported in Table IV are no longer consistently underestimated as in Table II, DFT errors ranging from negative to positive values. Changing from LDA to GGA functionals leads to a lengthening of all bonds by $0.02 \AA$. Thus, the addition of gradient terms corrects the roughly 10\% LDA underestimation of Pauli's repulsions ${ }^{71}$ and, hence, corrects rather short distances between the first-row transition metal and the ligand predicted by LDA. ${ }^{42}$ An alternative approach to the use of pure functionals refers to the use of functionals which include a mixture of HF exact exchange with DFT exchange correlation functional. For this system, the quality of the geometrical parameters yielded by a hybrid functional (B3P) is slightly inferior to that obtained from an also nonlocal yet pure functional (BP).

Comparison of Tables III and IV shows an improvement in DFT results for bond angles, which are now reproduced to within $\sim 1^{\circ}$. Interestingly, they are quite insensitive to the choice of the LDA or GGA method. ${ }^{23}$ In all cases, the $\angle \mathrm{OCrO}$ angle is predicted to be smaller than the $\angle \mathrm{FCrF}$ angle, in excellent agreement with the experimental results reported by Garner and Mather. ${ }^{66}$

As a whole, we have found that the molecular structure of the $\mathrm{CrO}_{2} \mathrm{~F}_{2}$ compound is not correctly described at the $\mathrm{HF}$ level. Post-HF methods based on the reference HF wave function do not systematically improve the HF results and can also yield important errors. In this compound, DFT methods offer more accurate geometries.

\section{Harmonic vibrational frequencies}

A second stage of this subsection, focuses on a comparative analysis from a vibrational-spectroscopic point of view. For $\mathrm{CrO}_{2} \mathrm{~F}_{2}$, there are nine normal modes of vibration; four of stretching $(\nu)$, two of bending $(\delta)$, two of rocking $(\sigma)$, and one of torsion $(\tau)$. Symmetry labels corresponding to each normal mode, together with vibrational frequencies and absorption intensities, are collected in Table V.

The average error for the harmonic frequencies computed at the HF level exceeds $23 \%$. Using basis set $\mathrm{B}$, the error is lower than $13.4 \%$, whereas using basis sets $\mathrm{A}, \mathrm{G}$, or

TABLE IV. Geometrical parameters for $\mathrm{CrO}_{2} \mathrm{~F}_{2}$ computed at DFT level. Bond distances in $\AA$ and angles in degrees.

\begin{tabular}{cccccc}
\hline \hline Functional/basis & Program & $r(\mathrm{Cr}-\mathrm{O})$ & $r(\mathrm{Cr}-\mathrm{F})$ & $\angle \mathrm{FCrF}$ & $\angle \mathrm{OCrO}$ \\
\hline VWN/G & $\mathrm{G} 92$ & 1.542 & 1.655 & 109.8 & 108.8 \\
BP/G & & 1.562 & 1.683 & 109.7 & 108.9 \\
B3P/G & & 1.535 & 1.665 & 109.6 & 108.8 \\
VWN/TZ+DZP & ADF & 1.570 & 1.701 & 111.2 & 108.3 \\
BP/TZ+DZP & & 1.591 & 1.724 & 111.3 & 108.1 \\
JMW/DNP & \multirow{2}{*}{ DMol } & 1.567 & 1.704 & 110.6 & 108.1 \\
BP/DNP & & 1.603 & 1.724 & 111.1 & 107.0 \\
Expt. $^{\mathrm{a}}$ & & 1.575 & 1.720 & 111.9 & 107.8 \\
\hline \hline
\end{tabular}

${ }^{\mathrm{a}}$ From Ref. 67. 
TABLE V. Vibrational frequencies (in $\mathrm{cm}^{-1}$ ) and absorption intensities ${ }^{\mathrm{a}}$ in parentheses (in $\mathrm{km} / \mathrm{mol}$ ) corresponding to the nine normal modes of $\mathrm{CrO}_{2} \mathrm{~F}_{2}$, computed at ab initio level.

\begin{tabular}{lccccccccc}
\hline \hline $\begin{array}{l}\text { Method/ } \\
\text { basis set }\end{array}$ & $\begin{array}{c}A_{1} \\
\left(\mathrm{CrX}_{2}\right)\end{array}$ & $\begin{array}{c}A_{2} \\
\tau\end{array}$ & $\begin{array}{c}B_{1} \\
\sigma\left(\mathrm{CrO}_{2}\right)\end{array}$ & $\begin{array}{c}B_{2} \\
\sigma\left(\mathrm{CrX}_{2}\right)\end{array}$ & $\begin{array}{c}A_{1} \\
\delta\left(\mathrm{CrO}_{2}\right)\end{array}$ & $\begin{array}{c}A_{1} \\
\nu\left(\mathrm{CrX}_{2}\right)\end{array}$ & $\begin{array}{c}B_{2} \\
\nu\left(\mathrm{CrX}_{2}\right)\end{array}$ & $\begin{array}{c}A_{1} \\
\nu\left(\mathrm{CrO}_{2}\right)\end{array}$ & $\begin{array}{c}B_{1} \\
\nu\left(\mathrm{CrO}_{2}\right)\end{array}$ \\
\hline RHF/A & 252.2 & 307.2 & 314.6 & 207.7 & 480.2 & 976.0 & 1001.8 & 1354.8 & 1286.9 \\
& $(4.1)$ & $(0.0)$ & $(3.9)$ & $(16.0)$ & $(0.1)$ & $(39.5)$ & $(106.5)$ & $(46.5)$ & $(49.2)$ \\
RHF/B & 211.1 & 296.0 & 294.6 & 356.9 & 537.8 & 728.5 & 714.4 & 1182.9 & 971.6 \\
& $(16.0)$ & $(0.0)$ & $(15.4)$ & $(19.8)$ & $(19.5)$ & $(108.6)$ & $(230.4)$ & $(152.9)$ & $(340.5)$ \\
RHF/G & 252.6 & 326.2 & 346.1 & 369.0 & 493.5 & 906.2 & 940.3 & 1361.3 & 1333.7 \\
& $(7.3)$ & $(0.0)$ & $(7.0)$ & $(18.1)$ & $(0.3)$ & $(124.1)$ & $(228.4)$ & $(144.7)$ & $(332.7)$ \\
RHF/J & 255.9 & 339.3 & 347.1 & 382.1 & 502.3 & 890.3 & 932.7 & 1323.6 & 1294.4 \\
& $(11.0)$ & $(0.0)$ & $(14.6)$ & $(25.3)$ & $(0.9)$ & $(139.9)$ & $(269.5)$ & $(170.8)$ & $(368.8)$ \\
MP2/G & 159.4 & 204.2 & 292.1 & 114.8 & 436.4 & 933.6 & 978.3 & 1652.3 & 1913.5 \\
& $\left(10^{-2}\right)$ & $(0.0)$ & $(7.3)$ & $(6.8)$ & $(0.0)$ & $(0.2)$ & $(105.4)$ & $(3291.5)$ & $(8540.1)$ \\
CISD/G & 236.1 & 305.5 & 321.9 & 335.7 & 466.2 & 870.9 & 915.6 & 1297.2 & 1268.3 \\
& $(5.6)$ & $(0.0)$ & $(5.1)$ & $(14.1)$ & $(0.1)$ & $(95.6)$ & $(207.3)$ & $(112.8)$ & $(236.2)$ \\
Expt. ${ }^{\text {b }}$ & 208 & 259 & 274 & 304 & 364 & 727 & 789 & 1006 \\
& $\cdots$ & $\cdots$ & $(\mathrm{S})$ & $(\mathrm{S})$ & $(\mathrm{W})$ & $(\mathrm{VS})$ & $(\mathrm{VS})$ & $(\mathrm{VS})$ \\
\hline \hline
\end{tabular}

${ }^{\mathrm{a} V S}$-very strong, S-strong, W-weak.

${ }^{\mathrm{b}}$ From Ref. 9.

$\mathrm{J}$ the error exceeds $26.7 \%$. However, the absorption intensities corresponding to bending modes predicted by basis set $\mathrm{B}$ are slightly too high. All-electron basis sets $\mathrm{G}$ and $\mathrm{J}$ have the advantage of predicting frequencies which are systematically above those experimentally observed, and furthermore the error is always of the same magnitude. Therefore, applying a correction factor of $0.85-0.95$ to harmonic vibrational frequencies ${ }^{72}$ it is possible to reproduce experimentally observed fundamentals.

The global error for spectroscopic results obtained at a post-HF level is larger than expected. For instance, the MP2 calculation clearly underestimates low frequencies and overestimates high frequencies, yielding an error $\sim 37.6 \%$. Such a deviation can be understood keeping in mind that the HF wave function, taken as a reference for the MP2 calculation, already exhibits some deficiencies. On the other hand, har- monic vibrational frequencies computed at CISD level (19.7\% error) are slightly better than HF frequencies computed with the same basis set. This notwithstanding, none of the HF or post-HF methods used manage to yield the correct increasing ordering of the vibrational frequencies.

Examining DFT frequencies from Table VI, all errors fall below $14.2 \%$ and, on average, do not exceed 9\%. Vibrational frequencies and absorption intensities fit the experimental pattern with better accuracy than previously seen for non-DFT procedures. This is not surprising at all from the structural parameters shown in Table IV, where optimized geometries already reproduced experimental data quite accurately. In general, the most important trends pointed out when analyzing results of Table IV can be seen again in Table VI. Thus, a change of the functional leads to the same conclusions as those mentioned in the previous section. For

TABLE VI. Vibrational frequencies (in $\mathrm{cm}^{-1}$ ) and absorption intensities ${ }^{\mathrm{a}}$ in parentheses (in $\mathrm{km} / \mathrm{mol}$ ) corresponding to the nine normal modes of $\mathrm{CrO}_{2} \mathrm{~F}_{2}$ computed at DFT level.

\begin{tabular}{|c|c|c|c|c|c|c|c|c|c|c|}
\hline Program & $\begin{array}{l}\text { Method/ } \\
\text { basis set }\end{array}$ & $\begin{array}{c}A_{1} \\
\delta\left(\mathrm{CrX}_{2}\right)\end{array}$ & $\begin{array}{c}A_{2} \\
\tau\end{array}$ & $\begin{array}{c}B_{1} \\
\sigma\left(\mathrm{CrO}_{2}\right)\end{array}$ & $\begin{array}{c}B_{2} \\
\sigma\left(\mathrm{CrX}_{2}\right)\end{array}$ & $\begin{array}{c}A_{1} \\
\delta\left(\mathrm{CrO}_{2}\right)\end{array}$ & $\begin{array}{c}A_{1} \\
\nu\left(\mathrm{CrX}_{2}\right)\end{array}$ & $\begin{array}{c}B_{2} \\
\nu\left(\mathrm{CrX}_{2}\right)\end{array}$ & $\begin{array}{c}A_{1} \\
\nu\left(\mathrm{CrO}_{2}\right)\end{array}$ & $\begin{array}{c}B_{1} \\
\nu\left(\mathrm{CrO}_{2}\right)\end{array}$ \\
\hline \multirow[t]{3}{*}{ G92 } & VWN/G & $\begin{array}{r}215.8 \\
(2.2)\end{array}$ & $\begin{array}{r}283.4 \\
(0.0)\end{array}$ & $\begin{array}{r}303.9 \\
(2.3)\end{array}$ & $\begin{array}{c}324.1 \\
(7.2)\end{array}$ & $\begin{array}{r}416.5 \\
(0.4)\end{array}$ & $\begin{array}{c}847.0 \\
(40.9)\end{array}$ & $\begin{array}{c}923.7 \\
(117.4)\end{array}$ & $\begin{array}{r}1144.3 \\
(75.8)\end{array}$ & $\begin{array}{l}1171.1 \\
(133.9)\end{array}$ \\
\hline & $\mathrm{BP} / \mathrm{G}$ & $\begin{array}{r}212.8 \\
(2.4)\end{array}$ & $\begin{array}{r}277.4 \\
(0.0)\end{array}$ & $\begin{array}{c}298.2 \\
(2.6)\end{array}$ & $\begin{array}{r}318.2 \\
(7.3)\end{array}$ & $\begin{array}{r}408.1 \\
(0.4)\end{array}$ & $\begin{array}{l}796.6 \\
(39.9)\end{array}$ & $\begin{array}{c}867.3 \\
(113.7)\end{array}$ & $\begin{array}{r}1094.1 \\
(71.0)\end{array}$ & $\begin{array}{l}1120.7 \\
(124.1)\end{array}$ \\
\hline & $\mathrm{B} 3 \mathrm{P} / \mathrm{G}$ & $\begin{array}{r}223.6 \\
(3.3)\end{array}$ & $\begin{array}{r}291.9 \\
(0.0)\end{array}$ & $\begin{array}{c}312.4 \\
(3.6)\end{array}$ & $\begin{array}{c}331.7 \\
(9.3)\end{array}$ & $\begin{array}{r}433.7 \\
(0.4)\end{array}$ & $\begin{array}{c}840.4 \\
(55.8)\end{array}$ & $\begin{array}{c}904.9 \\
(144.4)\end{array}$ & $\begin{array}{r}1175.5 \\
(88.9)\end{array}$ & $\begin{array}{c}1195.2 \\
(168.3)\end{array}$ \\
\hline \multirow[t]{2}{*}{$\mathrm{ADF}$} & VWN/TZDZP & $\begin{array}{r}228.7 \\
(2.6)\end{array}$ & $\begin{array}{r}265.9 \\
(0.0)\end{array}$ & $\begin{array}{c}276.7 \\
(4.0)\end{array}$ & $\begin{array}{r}298.7 \\
(6.3)\end{array}$ & $\begin{array}{r}412.3 \\
(0.3)\end{array}$ & $\begin{array}{l}755.6 \\
(49.5)\end{array}$ & $\begin{array}{c}850.6 \\
(131.4)\end{array}$ & $\begin{array}{r}1053.9 \\
(74.4)\end{array}$ & $\begin{array}{l}1075.8 \\
(139.8)\end{array}$ \\
\hline & BP/TZDZP & $\begin{array}{r}209.3 \\
(3.5)\end{array}$ & $\begin{array}{r}267.9 \\
(0.0)\end{array}$ & $\begin{array}{r}283.2 \\
(5.1)\end{array}$ & $\begin{array}{c}307.4 \\
(7.0)\end{array}$ & $\begin{array}{c}393.8 \\
(0.2)\end{array}$ & $\begin{array}{l}729.0 \\
(45.7)\end{array}$ & $\begin{array}{c}797.0 \\
(130.9)\end{array}$ & $\begin{array}{c}1012.9 \\
(75.8)\end{array}$ & $\begin{array}{l}1036.1 \\
(131.7)\end{array}$ \\
\hline \multirow[t]{2}{*}{$\mathrm{DMol}^{\mathrm{b}}$} & JMW/DNP & 220.8 & 281.6 & 288.6 & 313.0 & 407.9 & 753.6 & 820.3 & 1085.2 & 1107.3 \\
\hline & BP/DNP & 183.2 & 249.8 & 254.3 & 274.5 & 385.6 & 793.0 & 860.5 & 1123.3 & 1148.3 \\
\hline Expt. $^{c}$ & & $\begin{array}{r}208 \\
\ldots\end{array}$ & $\begin{array}{r}259 \\
\ldots\end{array}$ & $\begin{array}{l}274 \\
(S)\end{array}$ & $\begin{array}{r}304 \\
(\mathrm{~S})\end{array}$ & $\begin{array}{c}364 \\
(\mathrm{~W})\end{array}$ & $\begin{array}{l}727 \\
\text { (VS) }\end{array}$ & $\begin{array}{l}789 \\
\text { (VS) }\end{array}$ & $\begin{array}{l}1006 \\
\text { (VS) }\end{array}$ & $\begin{array}{l}1016 \\
\text { (VS) }\end{array}$ \\
\hline
\end{tabular}

${ }^{a}$ VS very strong, S-strong, W-weak.

${ }^{\mathrm{b}}$ Absorption intensities not available.

${ }^{\mathrm{c}}$ From Ref. 9. 
instance, the LDA approach exaggerates the bond strength because it underestimates Pauli's repulsions, leading to LDA frequencies higher than nonlocal frequencies, and also higher than the experimentally observed.

Among DFT calculations of Table VI, the minimum error $(2.3 \%)$ corresponds to a calculation which combines (1) a pure nonlocal functional and (2) a TZ+DZP quality basis set (the program being $\mathrm{ADF}$ ). In principle, such a good agreement could be attributed to a cancellation of errors or might be considered fortuitous, because the experimentally observed fundamentals are inherently anharmonic, whereas the present calculations correspond to harmonic vibrations. Indeed, without simplifying theoretical calculations through the harmonic approximation, computed frequencies would have been slightly different. Actually, the addition of anharmonic corrections usually has the effect of decreasing the calculated frequencies. The magnitude of this reduction is quite variable, e.g., for $\mathrm{CO}$, it is $27 \mathrm{~cm}^{-1}\left(\nu_{\mathrm{CO} \text { harm }}=2170\right.$ $\left.\mathrm{cm}^{-1}, \nu_{\mathrm{CO}}=2143 \mathrm{~cm}^{-1}\right){ }^{73}$ Therefore, should we add anharmonic corrections to calculated frequencies, they would probably become even closer to experimental values. ${ }^{74}$

\section{Electronic spectra}

An interesting point which has not received much attention in the literature concerns the relative stability of the low-lying electronic states for $\mathrm{CrO}_{2} \mathrm{~F}_{2}$. The lowest energy transitions are assigned as $\left(b_{1}, a_{2}, b_{2}\right) \rightarrow\left(a_{1}, a_{2}\right)$, yielding six singlet and six triplet excited states $\left(A_{1}, A_{2}, 2 B_{1}, 2 B_{2}\right)$. Excited energies corresponding to vertical transitions for the $\mathrm{CrO}_{2} \mathrm{~F}_{2}$ species have been computed at the HF, CASSCF $(12,11)$, and DFT levels of theory. We have found that all three methodologies yield that the first singly excited state has $B_{2}$ symmetry, which is in agreement with experimental investigations. The lowest singly excited state of $\mathrm{CrO}_{2} \mathrm{~F}_{2}$ was assigned from rotational analysis as ${ }^{1} B_{2}$ (Ref. 75) (accounting for a change of axes from the rotational system). The small separation between this state and nearby states deriving from the five other promotions can be taken as a good criterion for testing the accuracy of a given methodology. HF predicts a second singly excited state of ${ }^{1} A_{2}$ symmetry, whereas both correlated CASSCF and DFT energies agree in yielding a ${ }^{1} B_{1}$ state. Taking into account a previous study of $\mathrm{CrO}_{2} \mathrm{Cl}_{2}$ using the symmetry adapted cluster-configuration interaction method, ${ }^{76}$ the latter symmetry is likely more reliable than the former.

Another comparison between different levels and conditions of calculation can be made from Table VII, where the energetic difference between the ground state and the first excited state computed by each methodology is analyzed. The experimental gap is reported to be $2.6 \mathrm{eV} ;{ }^{77}$ our post-HF calculations yield a reasonable energy of $2.74 \mathrm{eV}$, whereas HF yields $4.5 \mathrm{eV}$, clearly overestimating the gap, and DFT yields an intermediate energy of $3.23 \mathrm{eV}$. HF results remarkably differ from experiment. DFT energies fall within the expected error range for this kind of determination (about $\pm 0.5 \mathrm{eV}$ ). Noticeably, better results are obtained when nonlocal functionals are used. Foresman et al. ${ }^{78}$ reported that the
TABLE VII. Comparison of the calculated and experimental energies (in $\mathrm{eV}$ ) for the lowest energy transition in $\mathrm{CrO}_{2} \mathrm{~F}_{2}$.

\begin{tabular}{clc}
\hline \hline Method & \multicolumn{1}{c}{ Conditions } & $\Delta E_{\text {exc }}$ \\
\hline HF & Basis G & 4.46 \\
CASSCF & Basis G & 2.74 \\
DFT & VWN/TZ+DZP & 3.29 \\
& BP/TZ+DZP & 3.23 \\
& BP/TZ+DZ & 3.17 \\
Expt. $^{a}$ & & 2.6 \\
\hline \hline
\end{tabular}

${ }^{\mathrm{a}}$ From Ref. 77.

effect of adding polarization functions decreases the accuracy of adiabatic and vertical transition energies while increasing the accuracy of excited state potential energy surfaces. Results from Table VII show that, here, omission of a polarization function changes the excitation energy only marginally. The best predictions are yielded by CASSCF.

The general improvement observed when changing from $\mathrm{HF}$ to CASSCF is mainly due to the favorable composition of the active space. As mentioned above, such a composition causes a correct structural description of the $\angle \mathrm{OCrO}$ angle (but not the $\angle \mathrm{FCrF}$ angle). It also accounts for the good agreement found with the experimental energy of the HOMO-LUMO transition, because in our $\operatorname{CASSCF}(12,11)$ calculation the chosen outer orbitals of chromium and oxygen are precisely those directly related to this transition. Moreover, the two lowest CASSCF energies (2.74 and 2.90 $\mathrm{eV}$ ) are accurate enough to suggest that the experimentally reported band I of $\mathrm{CrO}_{2} \mathrm{~F}_{2}$ electronic spectrum, which was found to be approximately centered at $2.6 \mathrm{eV},{ }^{77}$ can be actually assigned to the six transitions derived from the parent $1 t_{1} \rightarrow 2 e$ transition in $\mathrm{CrO}_{4}^{2-}$ (vide infra). Our DFT calculations locate this band at a slightly higher energy (3.23 and $3.35 \mathrm{eV}$ ). The deviation is attributed to the tendency of DFT to yield electronic transition energies above experimental data. $^{29}$

\section{Computational cost}

So far, only the quality of results has been analyzed. Above discussions have dealt with the accuracy yielded by each method, highlighting DFT and CASSCF as the better candidates to perform our analysis of $\mathrm{CrO}_{2} \mathrm{X}_{2}$ species. Another important aspect refers to the computational effort spent on reaching such accuracy.

Inclusion of electron correlation effects in computational chemistry is expensive. One of the most remarkable features of DFT is said to be its low cost in relation to post-HF methods. ${ }^{29}$ We have compared the CPU times required to evaluate the energy and gradient for the particular case of $\mathrm{CrO}_{2} \mathrm{~F}_{2}$ by means of different methodologies using the 88function basis set $\mathrm{G}$. All calculations have been done under the same conditions, identical basis set and direct SCF (i.e., recalculating the integrals in each SCF cycle), irrespective of the program. Tests have been run on an IBM Risc/6000-355 computer. 
TABLE VIII. Comparison of CPU times ${ }^{\mathrm{a}}$ for $\mathrm{CrO}_{2} \mathrm{~F}_{2}$ system computed through different methods. The time spent at $\mathrm{HF}$ level is taken as reference.

\begin{tabular}{ccc}
\hline \hline Method $^{\mathrm{b}}$ & $\begin{array}{c}\text { Relative time } \\
(E+\text { grad })\end{array}$ & $\begin{array}{c}E / E+\text { grad } \\
\text { time\% }\end{array}$ \\
\hline HF & 1.0 & 53.1 \\
MP2 & 4.3 & 30.4 \\
CISD & 92.0 & 60.2 \\
CASSCF(12,11) & 67.3 & 94.6 \\
DFT/VWN & 3.7 & 88.4 \\
DFT/BP & 4.2 & 81.7 \\
\hline \hline
\end{tabular}

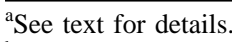

${ }^{\mathrm{b}}$ All calculations were done using GAUSSIAN 92, except $\operatorname{CASSCF}(12,11)$ using GAMESS.

Table VIII gathers the relative times needed to make a single-point calculation. We have focused our attention to the calculation of energy plus gradients because they are essential to optimize geometries, and further to determine vibrational frequencies. For the sake of clarity, times have been scaled to time spent at HF level. The reported values do not correspond to a unique SCF cycle, but to the total time spent to reach self-consistency.

From non-DFT results, it can be deduced that the time increases gradually and proportionally to the complexity of the calculation. Looking at the first column, DFT methods are about 6 times more expensive than HF, and in turn the CI/CASSCF are 15-20 times more expensive than DFT. From the percentages shown, the time spent on calculating the gradient is large for MP2, medium for SCF and CI, and small for the other methods. The percentage of time needed to compute the energy with respect to energy plus gradients through the CASSCF method is the largest because this method optimizes at the same time the MO and CI coefficients. As seen in the first column, the MP2 calculations take as much time as DFT does. Noteworthy, the comparison between local and nonlocal DFT results leads to the conclusion that including gradient corrections to the functionals makes the calculations slightly more expensive, but the improvement of the quality of results largely compensates for this small decrease on the computational speed as a result of adding nonlocal corrections. On the contrary, the CASSCF $(12,11)$ calculations become too expensive but do not yield the quality offered by DFT for the compound studied here, at least regarding geometries. By increasing the active space one could finally reach the desired accuracy, but then the CPU time would hugely increase as well. Therefore, DFT is an efficient methodology for the $\mathrm{CrO}_{2} \mathrm{~F}_{2}$ compound, in addition to being accurate enough.

Calculations presented in the next part of this article have been performed through nonlocal DFT. In particular, among the more reliable conditions of calculation, the BP functional and the TZ+DZP quality basis set as implemented in the ADF program have been selected.

\section{B. The family of compounds $\mathrm{CrO}_{2} \mathrm{X}_{2}(\mathrm{X}=\mathrm{F}, \mathrm{Cl}, \mathrm{Br}, \mathrm{I})$}

The goal of this section is the proper characterization (both structural and spectroscopic) of the full $\mathrm{CrO}_{2} \mathrm{X}_{2}$ series
TABLE IX. Geometrical parameters for $\mathrm{CrO}_{2} \mathrm{X}_{2}$ compounds. Bond distances in $\AA$ and bond angles in degrees.

\begin{tabular}{cccccc}
\hline \hline Species & $r(\mathrm{Cr}-\mathrm{O})$ & $r(\mathrm{Cr}-\mathrm{X})$ & $\angle \mathrm{XCrX}$ & $\angle \mathrm{OCrO}$ & Source \\
\hline $\mathrm{CrO}_{2} \mathrm{~F}_{2}$ & 1.591 & 1.724 & 111.3 & 108.1 & calc. \\
& 1.575 & 1.720 & 111.9 & 107.8 & expt. $^{\mathrm{a}}$ \\
$\mathrm{CrO}_{2} \mathrm{Cl}_{2}$ & 1.585 & 2.131 & 110.6 & 109.2 & calc. \\
& 1.581 & 2.126 & 113.3 & 108.5 & expt. $^{\mathrm{b}}$ \\
$\mathrm{CrO}_{2} \mathrm{Br}_{2}$ & 1.589 & 2.262 & 110.6 & 109.6 & calc. \\
& $\cdots$ & $\cdots$ & $\cdots$ & $\cdots$ & $\cdots$ \\
$\mathrm{CrO}_{2} \mathrm{I}_{2}$ & 1.595 & 2.507 & 114.8 & 111.5 & calc. \\
& $\cdots$ & $\cdots$ & $\cdots$ & $\cdots$ & $\cdots$ \\
\hline \hline
\end{tabular}

${ }^{\mathrm{a}}$ From Ref. 67

${ }^{\mathrm{b}}$ From Ref. 4.

of molecules. We begin with a detailed examination of molecular geometries and vibrational frequencies. After that, the UV/vis spectra are analyzed. For some of these chromium compounds, there is still a lack of experimental data, and hence our corresponding theoretical results are useful as predictions. Finally, attention is focused to the rationalization of the reported geometrical parameters for $\mathrm{CrO}_{2} \mathrm{X}_{2}$, in contrast to $\mathrm{SO}_{2} \mathrm{~F}_{2}$, by means of Bader analyses based on the charge density.

\section{Molecular structures}

As seen in Table IX, the agreement between calculated and observed parameters (available just for $\mathrm{X}=\mathrm{F}^{67}$ and $\mathrm{X}=\mathrm{Cl}^{4}$ ) is satisfactory for both bond angles and bond lengths, the only exception being the calculated $\angle \mathrm{ClCrCl}$ angle, which deviates by $2.7^{\circ}$. On the whole, the average error for bond distances of this two species is inferior to $0.008 \AA$, and for bond angles is smaller than $3^{\circ}$. Regarding $\mathrm{X}=\mathrm{Br}, \mathrm{I}$, despite the lack on experimental references, it is found that the $\mathrm{Cr}-\mathrm{X}$ distances follow the expected trend of increasing with an increase on the halogen atomic volume. About $\mathrm{Cr}-\mathrm{O}$ distances, changing the halogen from $\mathrm{F}$ to I has a very minor effect.

\section{Harmonic vibrational frequencies}

As far as experimental vibrational spectroscopic data are concerned, they have been reported only for the two lightest members. ${ }^{9,79}$ Several assignments have also been made for $\mathrm{CrO}_{2} \mathrm{Br}_{2},{ }^{9}$ reporting frequencies corresponding to the higher energetic region of the IR spectrum. No experimental data for $\mathrm{CrO}_{2} \mathrm{I}_{2}$ are available yet.

Results from Table X can be analyzed by columns or by rows. First, it is useful to consider metal-ligand bonds as diatomic molecules, described by the harmonic oscillator model. Under this consideration, two parameters are responsible for the behavior of the frequencies along the halogen series: the mass and the force constant. It is found that the heavier the halogen, the lower the vibrational frequency. For instance, the frequencies related to the normal mode $\nu\left(\mathrm{MX}_{2}\right)$ $B_{2}$ gradually decrease from $\mathrm{F}$ to I. This is precisely the expected behavior according to the halogen masses. For the same reason, it is not surprising that the symmetric and an- 
TABLE X. Vibrational frequencies (in $\mathrm{cm}^{-1}$ ) and absorption intensities ${ }^{\mathrm{a}}$ in parentheses (in $\mathrm{km} / \mathrm{mol}$ ) corresponding to the nine normal modes of $\mathrm{CrO}_{2} \mathrm{X}_{2}$ compounds $(\mathrm{X}=\mathrm{F}, \mathrm{Cl}, \mathrm{Br}, \mathrm{I})$, together with their labels of symmetry.

\begin{tabular}{|c|c|c|c|c|c|c|c|c|c|c|}
\hline Species & $\begin{array}{c}A_{1} \\
\delta\left(\mathrm{CrX}_{2}\right)\end{array}$ & $\begin{array}{c}A_{2} \\
\tau\end{array}$ & $\begin{array}{c}B_{1} \\
\sigma\left(\mathrm{CrO}_{2}\right)\end{array}$ & $\begin{array}{c}B_{2} \\
\sigma\left(\mathrm{CrX}_{2}\right)\end{array}$ & $\begin{array}{c}A_{1} \\
\delta\left(\mathrm{CrO}_{2}\right)\end{array}$ & $\begin{array}{c}A_{1} \\
\nu\left(\mathrm{CrX}_{2}\right)\end{array}$ & $\begin{array}{c}B_{2} \\
\nu\left(\mathrm{CrX}_{2}\right)\end{array}$ & $\begin{array}{c}A_{1} \\
\nu\left(\mathrm{CrO}_{2}\right)\end{array}$ & $\begin{array}{c}B_{1} \\
\nu\left(\mathrm{CrO}_{2}\right)\end{array}$ & Source \\
\hline \multirow{2}{*}{$\mathrm{CrO}_{2} \mathrm{~F}_{2}$} & $\begin{array}{r}209.3 \\
(3.5)\end{array}$ & $\begin{array}{r}267.9 \\
(0.0)\end{array}$ & $\begin{array}{r}283.2 \\
(5.1)\end{array}$ & $\begin{array}{c}307.4 \\
(7.0)\end{array}$ & $\begin{array}{r}393.8 \\
(0.2)\end{array}$ & $\begin{array}{l}729.0 \\
(45.7)\end{array}$ & $\begin{array}{c}797.0 \\
(130.9)\end{array}$ & $\begin{array}{r}1012.9 \\
(75.7)\end{array}$ & $\begin{array}{l}1036.1 \\
(131.7)\end{array}$ & calc. \\
\hline & $\begin{array}{r}208 \\
\ldots\end{array}$ & $\begin{array}{r}259 \\
\ldots\end{array}$ & $\begin{array}{r}274 \\
(\mathrm{~S})\end{array}$ & $\begin{array}{r}304 \\
(\mathrm{~S})\end{array}$ & $\begin{array}{l}364 \\
(\mathrm{~W})\end{array}$ & $\begin{array}{l}727 \\
\text { (VS) }\end{array}$ & $\begin{array}{l}789 \\
\text { (VS) }\end{array}$ & $\begin{array}{l}1006 \\
\text { (VS) }\end{array}$ & $\begin{array}{l}1016 \\
\text { (VS) }\end{array}$ & expt. $^{\mathrm{b}}$ \\
\hline \multirow[b]{2}{*}{$\mathrm{CrO}_{2} \mathrm{Cl}_{2}$} & $\begin{array}{l}137.7 \\
\left(10^{-2}\right)\end{array}$ & $\begin{array}{r}208.4 \\
(0.0)\end{array}$ & $\begin{array}{r}215.0 \\
(0.2)\end{array}$ & $\begin{array}{r}255.0 \\
(0.5)\end{array}$ & $\begin{array}{c}349.0 \\
(2.4)\end{array}$ & $\begin{array}{l}458.9 \\
(10.2)\end{array}$ & $\begin{array}{l}498.4 \\
(94.4)\end{array}$ & $\begin{array}{c}1022.4 \\
(78.3)\end{array}$ & $\begin{array}{c}1047.2 \\
(101.2)\end{array}$ & calc. \\
\hline & $\begin{array}{c}139 \\
\ldots\end{array}$ & $\begin{array}{c}212 \\
\ldots\end{array}$ & $\begin{array}{c}224 \\
\ldots\end{array}$ & $\begin{array}{c}257 \\
\ldots\end{array}$ & $\begin{array}{c}356 \\
\ldots\end{array}$ & $\begin{array}{l}470 \\
\text { (VS) }\end{array}$ & $\begin{array}{l}503 \\
\text { (VS) }\end{array}$ & $\begin{array}{l}991 \\
\text { (VS) }\end{array}$ & $\begin{array}{l}1002 \\
\text { (VS) }\end{array}$ & \multirow[t]{2}{*}{ expt. $^{\mathrm{c}}$} \\
\hline \multirow{2}{*}{$\mathrm{CrO}_{2} \mathrm{Br}_{2}$} & $\begin{array}{l}95.4 \\
(0.2)\end{array}$ & $\begin{array}{r}193.5 \\
(0.0)\end{array}$ & $\begin{array}{l}183.0 \\
\left(10^{-4}\right)\end{array}$ & $\begin{array}{c}219.1 \\
(0.1)\end{array}$ & $\begin{array}{c}272.0 \\
(2.3)\end{array}$ & $\begin{array}{r}409.6 \\
(1.6)\end{array}$ & $\begin{array}{l}415.6 \\
(69.8)\end{array}$ & $\begin{array}{r}1011.9 \\
(84.3)\end{array}$ & $\begin{array}{r}1037.9 \\
(93.5)\end{array}$ & \\
\hline & $\begin{array}{l}\cdots \\
\cdots\end{array}$ & $\begin{array}{l}\cdots \\
\cdots\end{array}$ & $\begin{array}{l}\cdots \\
\cdots\end{array}$ & $\begin{array}{l}\cdots \\
\cdots\end{array}$ & $\begin{array}{r}305 ? \\
\ldots\end{array}$ & $\begin{array}{r}399 \\
\ldots\end{array}$ & $\begin{array}{l}403 \\
\text { (VS) }\end{array}$ & $\begin{array}{l}983 \\
\text { (VS) }\end{array}$ & $\begin{array}{l}995 \\
\text { (VS) }\end{array}$ & expt. \\
\hline \multirow{3}{*}{$\mathrm{CrO}_{2} \mathrm{I}_{2}$} & $\begin{array}{l}71.5 \\
(0.4)\end{array}$ & $\begin{array}{r}189.3 \\
(0.0)\end{array}$ & $\begin{array}{l}166.2 \\
\left(10^{-3}\right)\end{array}$ & $\begin{array}{r}191.7 \\
(1.4)\end{array}$ & $\begin{array}{r}205.4 \\
(0.7)\end{array}$ & $\begin{array}{c}380.2 \\
(0.2)\end{array}$ & $\begin{array}{c}350.0 \\
(63.7)\end{array}$ & $\begin{array}{l}996.1 \\
(91.4)\end{array}$ & $\begin{array}{r}1023.9 \\
(99.9)\end{array}$ & calc. \\
\hline & $\cdots$ & $\cdots$ & $\cdots$ & $\cdots$ & $\cdots$ & $\cdots$ & $\cdots$ & $\cdots$ & $\cdots$ & \multirow{2}{*}{ expt. } \\
\hline & $\ldots$ & $\cdots$ & $\ldots$ & $\ldots$ & $\ldots$ & $\ldots$ & $\ldots$ & $\ldots$ & $\ldots$ & \\
\hline
\end{tabular}

${ }^{a}$ VS-very strong, S-strong, W-weak.

${ }^{\mathrm{b}}$ From Ref. 9.

${ }^{c}$ From Ref. 76.

tisymmetric $\mathrm{Cr}-\mathrm{O}$ stretching vibrations (columns 8 and 9 , respectively) appear at frequencies higher than those of the two analogous $\mathrm{Cr}-\mathrm{X}$ vibrations (columns 6 and 7), because all halogen atoms are heavier than oxygen atom.

When in a given vibration the halogen atom plays an unimportant role, then the force constant becomes quite determining. In such cases, the ordering of frequencies is less clear than before. Thus, for vibration $\nu\left(\mathrm{MO}_{2}\right) A_{1}$, the theoretical frequency of $\mathrm{CrO}_{2} \mathrm{~F}_{2}$ should be higher than for $\mathrm{CrO}_{2} \mathrm{Cl}_{2}$, yet it is not. This disagreement can be attributed to a failure of the structural parameters (Table IX), where the computed distance $\mathrm{Cr}-\mathrm{O}$ is already larger in $\mathrm{CrO}_{2} \mathrm{~F}_{2}$ than in $\mathrm{CrO}_{2} \mathrm{Cl}_{2}$, in disagreement with experiment.

If the analysis is now performed by rows, the mean deviations for $\mathrm{CrO}_{2} \mathrm{~F}_{2}$ and for $\mathrm{CrO}_{2} \mathrm{Cl}_{2}$ are 10 and $13 \mathrm{~cm}^{-1}$, respectively. In both cases, it leads to an average error of $<3 \%$. However, the sign of errors is not constant, so it is difficult to predict whether the experimental values for $\mathrm{X}=\mathrm{Br}$, I will appear above or below our computed frequencies. Examining Table X, only a hint is provided: for higher frequencies the calculated values exceed those experimentally observed, whereas for low frequencies, calculations underestimate experimental values.

As far as absorption intensities are concerned, there is a good agreement between theory and available experimental data. ${ }^{9,79}$ The derivative of the dipole moment with respect to the normal coordinate decreases when going from $\mathrm{F}$ to I, due to the decreasing charge separation in the $\mathrm{Cr}-\mathrm{X}$ bond along the series. Thus, for a given $\mathrm{Cr}-\mathrm{X}$ stretching frequency, the variation of the intensity along the series fits the expected change in the dipole moment with vibration. In $\mathrm{CrO}_{2} \mathrm{I}_{2}$, only the three highest vibrational frequencies are estimated to be very strong. On the basis of the known compounds, our theoretical predictions for $\mathrm{CrO}_{2} \mathrm{I}_{2}$ (and partially for $\mathrm{CrO}_{2} \mathrm{Br}_{2}$ ) spectra are reasonable approximations, awaiting for future experimental confirmation.

\section{Electronic spectra}

Since the $\mathrm{CrO}_{2} \mathrm{~F}_{2}$ system possesses an approximately tetrahedral configuration, there is a certain similarity between spectroscopic results obtained for this species and those of the isoelectronic molecules $\mathrm{CrO}_{4}^{2-}$ or $\mathrm{MnO}_{4}^{-}$, belonging to $T_{d}$ point group. Thus, one can study the electronic spectra of $\mathrm{CrO}_{2} \mathrm{X}_{2}$ taking as reference $\mathrm{CrO}_{4}^{2-}$ and then perturbing the electronic structure by changing one or more of the oxygen ligands into halogen atoms $\left(\mathrm{CrO}_{4}^{2-} \rightarrow \mathrm{CrO}_{3} \mathrm{X}^{-} \rightarrow \mathrm{CrO}_{2} \mathrm{X}_{2}\right){ }^{7}$ However, there is some difficulty in establishing a direct correspondence between the MOs of these molecules ${ }^{76}$ because the reduction of the symmetry $\left(T_{d} \rightarrow C_{3 v} \rightarrow C_{2 v}\right)$ causes a mixture of the orbitals.

Figure 1 depicts a diagram of the energetic levels for the highest occupied orbitals and the lowest unoccupied orbitals for the ground state of $\mathrm{CrO}_{4}^{2-}\left(T_{d}\right), \mathrm{CrO}_{3} \mathrm{~F}^{-}\left(C_{3 v}\right)$, and $\mathrm{CrO}_{2} \mathrm{~F}_{2}\left(C_{2 v}\right)$. On the basis of $\mathrm{CrO}_{4}^{2-}$, the highest filled orbitals of $\mathrm{CrO}_{2} \mathrm{~F}_{2}$ derive from the correlation $t_{1}\left(T_{d}\right) \rightarrow a_{2}+b_{1}+b_{2}\left(C_{2 v}\right)$, whereas the two lowest empty orbitals have symmetries $a_{1}$ and $a_{2}$ with the former being lower lying, and follow the correlation $e\left(T_{d}\right) \rightarrow a_{1}+a_{2}\left(C_{2 v}\right)$. The lowest experimental energy transitions are $1 t_{1} \rightarrow 2 e$ for $\mathrm{CrO}_{4}^{2-}(3.3 \mathrm{eV}),{ }^{80} 1 a_{2} \rightarrow 9 e$ for $\mathrm{CrO}_{3} \mathrm{~F}^{-}(2.8 \mathrm{eV}),{ }^{81}$ and $7 b_{2} \rightarrow 14 a_{1}$ for $\mathrm{CrO}_{2} \mathrm{~F}_{2}(2.6 \mathrm{eV}) .^{77}$

Table XI shows the distributions of electronic charge for the ground-state frontier orbitals of $\mathrm{CrO}_{2} \mathrm{~F}_{2}$. As far as the numeration of the orbitals is concerned, it is important to note that, for instance, the orbital we have labeled $5 b_{2}$ corresponds to the orbital reported as $7 b_{2}$ in the literature. ${ }^{7}$ This 


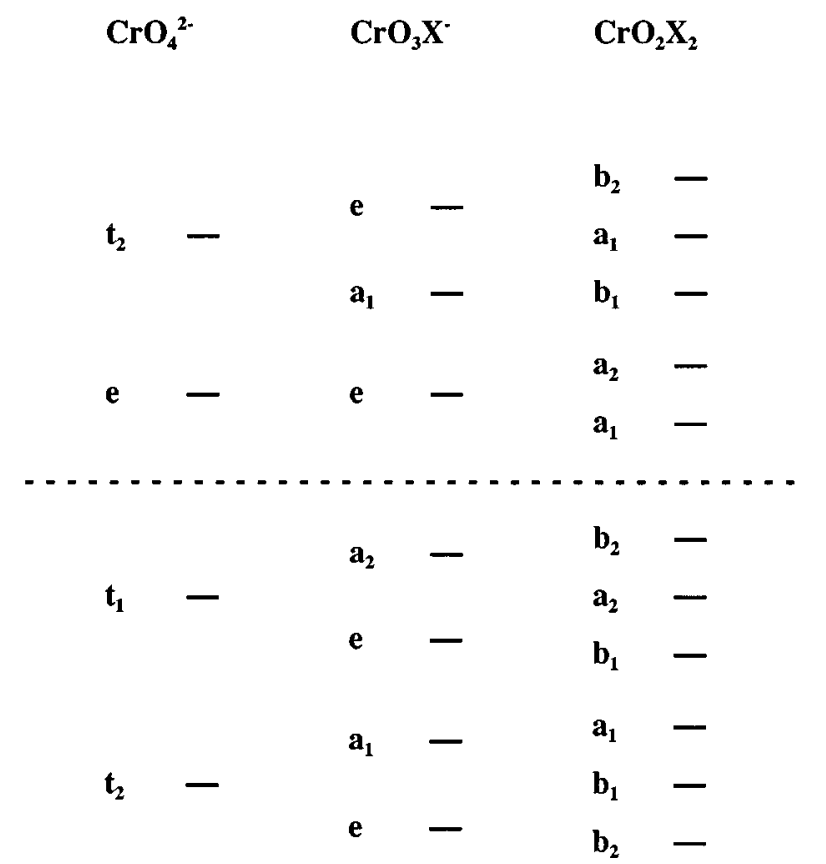

FIG. 1. Energy level diagram for the higher occupied and lower unoccupied orbitals in the ground states of $\mathrm{CrO}_{4}^{2-}\left(T_{d}\right), \mathrm{CrO}_{3} \mathrm{X}^{-}\left(C_{3 v}\right)$, and $\mathrm{CrO}_{2} \mathrm{X}_{2}\left(C_{2 v}\right)$. The three highest filled orbitals of $b_{2}, a_{2}$, and $b_{1}$ symmetry in $\mathrm{CrO}_{2} \mathrm{X}_{2}$ have the order shown for $\mathrm{X}=\mathrm{F}, \mathrm{Cl}$ but they follow the ordering $a_{2}>b_{1}>b_{2}$ for $\mathrm{X}=\mathrm{Br}, \mathrm{I}$.

is due to the omission of core orbitals in our numeration. All indices are, then, shifted.

The highest occupied orbitals derive from the correlation $1 t_{1}\left(T_{d}\right) \rightarrow 2 a_{2}+5 b_{1}+5 b_{2}\left(C_{2 v}\right)$, having a relative energy ordering $5 b_{2}>2 a_{2}>5 b_{1}$ and only slight chromium character. Among these, the $5 b_{2}$ has the greatest oxygen amplitude and the smallest halogen amplitude, so that the highest occupied orbital is still mainly an oxygen lone pair. The two lowest unfilled orbitals belong to the species of symmetry $a_{1}$ and $a_{2}$, with the former being lower lying, and are mainly of chromium $3 d$ character. This follows again from the correlation $e\left(T_{d}\right) \rightarrow a_{1}+a_{2}\left(C_{2 v}\right)$. The $9 a_{1}$ orbital has greater chromium and fluorine character and smaller oxygen character than the $3 a_{2}$ orbital. Our relative contributions to each orbital shown in Table XI are in good agreement with the calculations previously reported by Miller, Tinti, and Case ${ }^{7}$ using the $X \alpha$-scattered wave method.

From an experimental point of view, most of the electronic spectroscopy information is focused on $\mathrm{CrO}_{2} \mathrm{Cl}_{2}$, and
TABLE XI. Electronic charge distributions (in a.u.) for the ground-state orbitals of $\mathrm{CrO}_{2} \mathrm{~F}_{2}$ that take part in the studied excitations.

\begin{tabular}{cccc}
\hline \hline Orbital & Cr charge & O charge & F charge \\
\hline $3 a_{2}$ & 0.5832 & 0.3566 & 0.0601 \\
$9 a_{1}$ & 0.6377 & 0.2196 & 0.1426 \\
$5 b_{2}$ & 0.0075 & 0.9576 & 0.0350 \\
$2 a_{2}$ & 0.0875 & 0.4420 & 0.4705 \\
$5 b_{1}$ & 0.0561 & 0.6539 & 0.2901 \\
\hline \hline
\end{tabular}

secondarily, on $\mathrm{CrO}_{2} \mathrm{~F}_{2}$. (The latter has partially been dealt with in Sec. III A 3). Table XII gathers the orbital energies for the ground-state of $\mathrm{CrO}_{2} \mathrm{~F}_{2}, \mathrm{CrO}_{2} \mathrm{Cl}_{2}, \mathrm{CrO}_{2} \mathrm{Br}_{2}$, and $\mathrm{CrO}_{2} \mathrm{I}_{2}$. The two orbitals above the dashed line of the table derive from the $e\left(T_{d} \rightarrow a_{1}+a_{2}\left(C_{2 v}\right)\right.$ correlation, as in $\mathrm{CrO}_{2} \mathrm{~F}_{2}$. In the same way, the three orbitals below the dashed line arise from the $1 t_{1}\left(T_{d}\right) \rightarrow 2 a_{1}+5 b_{1}+5 b_{2}\left(C_{2 v}\right)$ correlation, but unlike in $\mathrm{CrO}_{2} \mathrm{~F}_{2}$, they do not longer have a predominant character of oxygen; the halogen contribution increases now from $\mathrm{Cl}$ to I, exceeding the oxygen contribution.

The six excitations derived from the parent $1 t_{1} \rightarrow 2 e$ transition have been collected in Table XIII. Among these excitations, the most interesting transition corresponds to that involving a lower energy, namely, the $5 b_{2} \rightarrow 9 a_{1}$ for $\mathrm{CrO}_{2} \mathrm{Cl}_{2}$, the $7 b_{2} \rightarrow 12 a_{1}$ for $\mathrm{CrO}_{2} \mathrm{Br}_{2}$, and the $4 a_{2} \rightarrow 12 a_{1}$ for $\mathrm{CrO}_{2} \mathrm{I}_{2}$. Noticeably, for $\mathrm{X}=\mathrm{F}, \mathrm{Cl}$, I such a transition takes place between HOMO and LUMO orbitals, as expected, but not for $\mathrm{X}=\mathrm{Br}$, where the excitation of an electron from the $7 b_{2}$ orbital leads to a slightly lower energy $(2.42 \mathrm{eV})$ than exciting an electron from the HOMO $4 \mathrm{a}_{2}$ orbital $(2.50 \mathrm{eV})$.

Analyzing the calculated HOMO-LUMO transitions along the series, it is found that they gradually decrease from F to I $(3.23>2.69>2.50>1.92)$, which is correlated to the established order in the electrochemical series. The heavier the halogen atom, the less separated are the frontier orbitals in the molecule (Table XII). This is in agreement with the principle of maximum hardness ${ }^{82}$ which states that stability of chemical systems increases with larger HOMO-LUMO differences; soft molecules have a small energy gap, and hard molecules, a large gap. Therefore, our spectroscopic results confirm how unstable the $\mathrm{CrO}_{2} \mathrm{Br}_{2}$ compound is, and predict an even more difficult synthesis of $\mathrm{CrO}_{2} \mathrm{I}_{2}$.

The most detailed study on the experimental electronic spectrum of $\mathrm{CrO}_{2} \mathrm{Cl}_{2}$ was reported for the species in the gas phase, ${ }^{77}$ revealing a lowest excitation energy of $2.4 \mathrm{eV}$. Our computed gap for the HOMO-LUMO transition in the

TABLE XII. Ground-state orbital energies (in a.u.) for $\mathrm{CrO}_{2} \mathrm{X}_{2}(\mathrm{X}=\mathrm{F}, \mathrm{Cl}, \mathrm{Br}, \mathrm{I})$.

\begin{tabular}{|c|c|c|c|c|c|c|c|}
\hline \multicolumn{2}{|c|}{$\mathrm{CrO}_{2} \mathrm{~F}_{2}$} & \multicolumn{2}{|c|}{$\mathrm{CrO}_{2} \mathrm{Cl}_{2}$} & \multicolumn{2}{|c|}{$\mathrm{CrO}_{2} \mathrm{Br}_{2}$} & \multicolumn{2}{|c|}{$\mathrm{CrO}_{2} \mathrm{I}_{2}$} \\
\hline Orbital & E & Orbital & E & Orbital & E & Orbital & $\mathrm{E}$ \\
\hline $3 a_{2}$ & -0.2256 & $3 a_{2}$ & -0.2145 & $5 a_{2}$ & -0.2028 & $5 a_{2}$ & -0.1930 \\
\hline $9 a_{1}$ & -0.2379 & $9 a_{1}$ & -0.2336 & $12 a_{1}$ & -0.2234 & $12 a_{1}$ & -0.2172 \\
\hline $5 b_{2}$ & -0.3353 & $5 b_{2}$ & -0.3190 & $4 a_{2}$ & -0.2988 & $4 a_{2}$ & -0.2711 \\
\hline $2 a_{2}$ & -0.3741 & $2 a_{2}$ & -0.3237 & $8 b_{1}$ & -0.2996 & $8 b_{1}$ & -0.2732 \\
\hline $5 b_{1}$ & -0.3749 & $5 b_{1}$ & -0.3252 & $7 b_{2}$ & -0.3005 & $7 b_{2}$ & -0.2763 \\
\hline
\end{tabular}


TABLE XIII. Excitation energies (in eV) for the six lower transitions of $\mathrm{CrO}_{2} \mathrm{X}_{2}(\mathrm{X}=\mathrm{F}, \mathrm{Cl}, \mathrm{Br}, \mathrm{I})$.

\begin{tabular}{|c|c|c|c|c|c|c|c|c|c|c|c|}
\hline \multicolumn{3}{|c|}{$\mathrm{CrO}_{2} \mathrm{~F}_{2}$} & \multicolumn{3}{|c|}{$\mathrm{CrO}_{2} \mathrm{Cl}_{2}$} & \multicolumn{3}{|c|}{$\mathrm{CrO}_{2} \mathrm{Br}_{2}$} & \multicolumn{3}{|c|}{$\mathrm{CrO}_{2} \mathrm{I}_{2}$} \\
\hline Excitation & Sym & $\Delta E$ & Excitation & Sym & $\Delta E$ & Excitation & Sym & $\Delta E$ & Excitation & Sym & $\Delta E$ \\
\hline $2 a_{2} \rightarrow 3 a_{2}$ & ${ }^{1} A_{1}$ & 4.89 & $2 a_{2} \rightarrow 3 a_{2}$ & ${ }^{1} A_{1}$ & 3.92 & $4 a_{2} \rightarrow 5 a_{2}$ & ${ }^{1} A_{1}$ & 3.50 & $8 b_{1} \rightarrow 5 a_{2}$ & ${ }^{1} B_{2}$ & 3.00 \\
\hline $5 b_{1} \rightarrow 3 a_{2}$ & ${ }^{1} B_{2}$ & 4.66 & $5 b_{1} \rightarrow 3 a_{2}$ & ${ }^{1} B_{2}$ & 3.89 & $8 b_{1} \rightarrow 5 a_{2}$ & ${ }^{1} B_{2}$ & 3.48 & $4 a_{2} \rightarrow 5 a_{2}$ & ${ }^{1} A_{1}$ & 2.98 \\
\hline $2 a_{2} \rightarrow 9 a_{1}$ & ${ }^{1} A_{2}$ & 4.10 & $5 b_{2} \rightarrow 3 a_{2}$ & ${ }^{1} B_{1}$ & 3.20 & $7 b_{2} \rightarrow 5 a_{2}$ & ${ }^{1} B_{1}$ & 2.99 & $7 b_{2} \rightarrow 5 a_{2}$ & ${ }^{1} B_{1}$ & 2.78 \\
\hline $5 b_{1} \rightarrow 9 a_{1}$ & ${ }^{1} B_{1}$ & 4.07 & $5 b_{1} \rightarrow 9 a_{1}$ & ${ }^{1} B_{1}$ & 3.02 & $8 b_{1} \rightarrow 12 a_{1}$ & ${ }^{1} B_{1}$ & 2.56 & $7 b_{2} \rightarrow 12 a_{1}$ & ${ }^{1} B_{2}$ & 2.02 \\
\hline $5 b_{2} \rightarrow 3 a_{2}$ & ${ }^{1} B_{1}$ & 3.35 & $2 a_{2} \rightarrow 9 a_{1}$ & ${ }^{1} A_{2}$ & 2.93 & $4 a_{2} \rightarrow 12 a_{1}$ & ${ }^{1} A_{2}$ & 2.50 & $8 b_{1} \rightarrow 12 a_{1}$ & ${ }^{1} B_{1}$ & 1.98 \\
\hline $5 b_{2} \rightarrow 9 a_{1}$ & ${ }^{1} B_{2}$ & $3.23^{\mathrm{a}}$ & $5 b_{2} \rightarrow 9 a_{1}$ & ${ }^{1} B_{2}$ & $2.69^{\mathrm{b}}$ & $7 b_{2} \rightarrow 12 a_{1}$ & ${ }^{1} B_{2}$ & 2.42 & $4 a_{2} \rightarrow 12 a_{1}$ & ${ }^{1} A_{2}$ & 1.92 \\
\hline
\end{tabular}

${ }^{\mathrm{a}}$ Experimental value in Ref. 77 is $2.6 \mathrm{eV}$.

${ }^{\mathrm{b}}$ Experimental value in Ref. 77 is $2.4 \mathrm{eV}$.

$\mathrm{CrO}_{2} \mathrm{Cl}_{2}$ overestimates the observed value by $0.3 \mathrm{eV}$. Regarding $\mathrm{CrO}_{2} \mathrm{~F}_{2}$, the deviation error sign is also positive. Thus, the predicted values of 2.50 and $1.92 \mathrm{eV}$ for $\mathrm{CrO}_{2} \mathrm{Br}_{2}$ and $\mathrm{CrO}_{2} \mathrm{I}_{2}$, respectively, must be taken with caution; experimental evidence will probably reveal, when available, slightly lower energies.

$\mathrm{CrO}_{2} \mathrm{~F}_{2}$ is reported to be a volatile violet-red solid, subliming at $29.6{ }^{\circ} \mathrm{C}$ to give an orange vapor. ${ }^{83}$ Charge transfer bands in the visible region of the spectrum are possible when ligands have nonshared electron pairs of high energy (like the oxygen or the halogen atoms here) and the metal has low empty orbitals. Although we have not computed their oscillator strengths, the studied excitation energies correspond to dipole-allowed transitions, so the calculated excitation energies for $\mathrm{CrO}_{2} \mathrm{X}_{2}$ show that these species absorb in the spectral region ranging $450-650 \mathrm{~nm}$, and suggest that they are likely to be colored compounds in the gas phase (from an orange $\mathrm{CrO}_{2} \mathrm{~F}_{2}$ to purple-reddish $\mathrm{CrO}_{2} \mathrm{Br}_{2}$ and $\mathrm{CrO}_{2} \mathrm{I}_{2}$ ).

\section{Rationalization of bond angles by means of Bader analyses}

Unlike $\mathrm{SO}_{2} \mathrm{~F}_{2}$, the structure of $\mathrm{CrO}_{2} \mathrm{X}_{2}$ compounds does not agree with the VSEPR theoretical predictions. The expected trend for bond angles on the basis of this model is $\angle \mathrm{XCrX}<\angle \mathrm{OCrO}$. However, both experiment and calculations disagree with VSEPR and predict an opposite behavior for the four chromium (VI) dioxodihalides (see Table IX). In order to clarify this disagreement, a topological analysis of the electronic distribution and a study of charges has been performed for $\mathrm{CrO}_{2} \mathrm{~F}_{2}$ and $\mathrm{SO}_{2} \mathrm{~F}_{2}$ at the DFT level using basis set $\mathrm{G}$. For the latter system, the $\angle \mathrm{FSF}$ and $\angle \mathrm{OSO}$ bond angles are $94.9^{\circ}$ and $125.0^{\circ}$, respectively, so the bond angle ordering is $\angle \mathrm{FSF} \angle \angle \mathrm{OSO}$, as predicted by the VSEPR model.

Electronic analyses of the density ${ }^{84,85}$ have become a widespread technique to analyze interactions between atoms in molecules. This kind of analysis is based on the study of the topological properties of electron density distributions and its derivatives (gradient vector and Laplacian). The socalled bond critical points (BCPs) exhibit a minimum value of electron density in a path connecting two nuclei but have an electron density maximum in a direction orthogonal to such a path. The BCPs of $\mathrm{CrO}_{2} \mathrm{~F}_{2}$ and $\mathrm{SO}_{2} \mathrm{~F}_{2}$ are collected in Table XIV, together with the Laplacian of the electron den- sity $\left(\nabla^{2} \rho_{\mathrm{BCP}}\right)$, and the ratio of the perpendicular contractions of the density to its parallel expansion $\left(\left|\lambda_{1}\right| / \lambda_{3}\right)$, which also provide important information on the nature of the chemical interaction between atoms. ${ }^{84}$ Thus, a representation of $\nabla^{2} \rho_{\mathrm{BCP}}$ exhibits spherical nodes in an atom (values of the radius for which $\nabla^{2} \rho_{\mathrm{BCP}}=0$ ), their number being related to the atomic shell structure. Negative values denote regions where electron density is locally concentrated while positive values involve regions where electron density is depleted.

The nature of the bonds in $\mathrm{CrO}_{2} \mathrm{~F}_{2}$ and $\mathrm{SO}_{2} \mathrm{~F}_{2}$ can be discussed from Table XIV. As far as $\mathrm{Cr}-\mathrm{O}$ and $\mathrm{S}-\mathrm{O}$ bonds are concerned, the kind of interaction is basically the same: a closed-shell interaction. Thus, in both cases $\nabla^{2} \rho_{\mathrm{BCP}}>1$, and $\left|\lambda_{1}\right| / \lambda_{3}<0.25$. Values are quite similar irrespective of the central atom being $\mathrm{Cr}$ or $\mathrm{S}$. On the other hand, when comparing $\mathrm{Cr}-\mathrm{F}$ and $\mathrm{S}-\mathrm{F}$ bonds, different types of interaction are found. The former can be classified as an ionic bond, while the latter exhibits the characteristics of covalent interactions. Two effects lead to this latter conclusion: First, the S-F bond has a negative value of the Laplacian at the $\mathrm{BCP}$, indicating that there is a considerable amount of electron density at the BCP between $\mathrm{S}$ and $\mathrm{F}$, whereas $\nabla^{2} \rho_{\mathrm{BCP}}$ for $\mathrm{Cr}-\mathrm{F}$ is positive. Second, $\left|\lambda_{1}\right| / \lambda_{3}$ for $S-F$ is just slightly lower than one, whereas for $\mathrm{Cr}-\mathrm{F}$ it is about four times smaller, showing that the chemical interactions are intermediate for $\mathrm{S}-\mathrm{F}$, yet closed-shell for $\mathrm{Cr}-\mathrm{F}$.

Mulliken charge distribution analyses of both compounds confirm the ionic nature of the $\mathrm{Cr}-\mathrm{F}$ bond. The charge separations in $\mathrm{CrO}_{2} \mathrm{~F}_{2}$ are especially outstanding $(\mathrm{Cr}$ $+2.20, \mathrm{O}-0.59, \mathrm{~F}-0.51$ ), whereas in $\mathrm{SO}_{2} \mathrm{~F}_{2}$ become less

TABLE XIV. Electronic analyses of the density ${ }^{\mathrm{a}}$ for $\mathrm{CrO}_{2} \mathrm{~F}_{2}$ and $\mathrm{SO}_{2} \mathrm{~F}_{2}$. $\rho_{\mathrm{BCP}}$ is the electron density at the BCP (in a.u.) and $\nabla^{2} \rho$ is the Laplacian of the electron density at the BCP (in a.u.). The value of the ratio between the perpendicular and the parallel curvatures $\left(\left|\lambda_{1}\right| / \lambda_{3}\right)^{\mathrm{b}}$ is also given.

\begin{tabular}{cccc}
\hline \hline Bond & $\rho_{\mathrm{BCP}}$ & $\nabla^{2} \rho_{\mathrm{BCP}}$ & $\left|\lambda_{1}\right| / \lambda_{3}$ \\
\hline $\mathrm{Cr}-\mathrm{F}$ & 0.1681 & 0.8798 & 0.1990 \\
$\mathrm{Cr}-\mathrm{O}$ & 0.2565 & 1.3573 & 0.2072 \\
$\mathrm{~S}-\mathrm{F}$ & 0.2091 & -0.2048 & 0.8530 \\
$\mathrm{~S}-\mathrm{O}$ & 0.2844 & 1.0242 & 0.2185 \\
\hline \hline
\end{tabular}

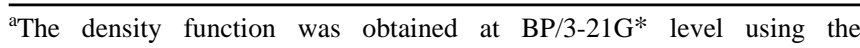
GAUSSIAN 92 program.

${ }^{b} \lambda_{1}$ and $\lambda_{3}$ are eigenvalues of the Hessian matrix at the BCP. 
pronounced ( $\mathrm{S}+1.17, \mathrm{O}-0.37, \mathrm{~F}-0.22$ ), leading to the conclusion that the repulsions between nonshared electron pairs of ligands when the central atom is a transition metal are basic to determine the stereochemistry of $\mathrm{CrO}_{2} \mathrm{~F}_{2}$; on the contrary, they are not taken into account by the VSEPR theory. Our reasons agree with the assumptions made by Garner and Mather ${ }^{66}$ from a study of charges. Consequently, it is suggested that the unexpectedly large $\angle \mathrm{FCrF}$ bond angle is partially caused by strong electrostatic repulsions between fluorine atoms, whose high concentrated density comes from a poorer ability of chromium $d$ orbitals to accommodate it, and from the influence of having a less electronegative $\mathrm{Cr}$ than $\mathrm{S}$ as the central atom.

\section{CONCLUSIONS}

Chromium (VI) dioxodihalides have been theoretically characterized from both the structural and spectroscopic (IR and UV/vis) points of view. Computed geometries, vibrational frequencies and excitation energies agree fairly well with experiment for $\mathrm{CrO}_{2} \mathrm{~F}_{2}$ and $\mathrm{CrO}_{2} \mathrm{Cl}_{2}$, whose previous investigations have been taken as reference. Thus, computed bond lengths and angles reproduce observed data within $0.008 \AA$ and $3^{\circ}$, respectively; harmonic IR frequencies deviate by an average error of only $3 \%$, and excitation energies corresponding to the visible spectrum fall within the expected margin of error for such a kind of determination. However, the most interesting conclusions concern the unknown $\mathrm{CrO}_{2} \mathrm{Br}_{2}$ and $\mathrm{CrO}_{2} \mathrm{I}_{2}$ species, for which predictions are made. Thus, for instance, the $\mathrm{Cr}-\mathrm{I}$ bond distance is expected to be about $2.5 \AA$, and the computed lowest excitation energy of $\mathrm{CrO}_{2} \mathrm{Br}_{2}(2.42 \mathrm{eV})$ and $\mathrm{CrO}_{2} \mathrm{I}_{2}(1.92 \mathrm{eV})$ suggests that the latter compound will be more reactive (less stable) than the former.

We have also performed a comparative systematic study on the $\mathrm{CrO}_{2} \mathrm{~F}_{2}$ compound, using different methodologies, in order to select the most appropriate computational way of carrying such an investigation. After a first stage, $\operatorname{CASSCF}(12,11)$ and DFT procedures have revealed themselves as the most suitable methods, according to the accuracy of results. A second aspect to be treated has concerned computational effort and requirements. Thus, it has been analyzed which efficiency each level of theory could offer. A compromise between both analyses has recommended use of DFT, since it showed to be accurate enough and simultaneously much more cost effective for studying properties of a medium-sized molecule like $\mathrm{CrO}_{2} \mathrm{~F}_{2}$, and, by analogy, suitable for the full $\mathrm{CrO}_{2} \mathrm{X}_{2}$ series.

Finally, as an interesting outset of the structural calculations, we have also investigated why the VSEPR theory is unable to reproduce correctly the molecular geometries of these species. The contradiction between the VSEPR model, computational predictions and experimental evidence has been elucidated on the basis of electronic analyses, comparing $\mathrm{CrO}_{2} \mathrm{~F}_{2}$ and $\mathrm{SO}_{2} \mathrm{~F}_{2}$ molecules. Values of the density at the bond critical points, together with information brought about by the Laplacian of the density, allow to conclude that the failure of the VSEPR theory in $\mathrm{CrO}_{2} \mathrm{X}_{2}$ is mainly due to the ionic nature of the $\mathrm{Cr}-\mathrm{F}$ bond in $\mathrm{CrO}_{2} \mathrm{~F}_{2}$, as compared to the intermediate character of the $\mathrm{S}-\mathrm{F}$ bond in $\mathrm{SO}_{2} \mathrm{~F}_{2}$, resulting in relevant coulombic repulsions between fluoride ligands.

\section{ACKNOWLEDGMENTS}

The present work has been founded through the Spanish DGICYT Project No. PB 92-0333. One of us (M.T.) gratefully acknowledges the financial support provided by the Comissionat per a Universitats i Recerca de la Generalitat de Catalunya through a fellowship.

${ }^{1}$ K. B. Sharpless and T. C. Flood, J. Am. Chem. Soc. 93, 2316 (1971).

${ }^{2}$ L. M. Hjelmeland and G. H. Loew, J. Am. Chem. Soc. 99, 3514 (1977).

${ }^{3}$ T. Ziegler and J. Li, Organometallics 14, 214 (1995).

${ }^{4}$ C. J. Marsden, L. Hedberg, and K. Hedberg, Inorg. Chem. 21, 1115 (1982).

${ }^{5}$ M. D. Spicer and N. A. Young, J. Chem. Soc., Dalton Trans. 1991, 3133.

${ }^{6}$ (a) L. M. Hjelmeland and G. H. Loew, J. Am. Chem. Soc. 99, 3514 (1977); (b) R. F. Kirchner and G. H. Loew, ibid. 99, 4639 (1977).

${ }^{7}$ R. M. Miller, D. S. Tinti, and D. A. Case, Inorg. Chem. 28, 2738 (1989).

${ }^{8}$ G. K. Cook and J. M. Mayer, J. Am. Chem. Soc. 117, 7139 (1995).

${ }^{9}$ E. G. Hope, W. Levason, J. S. Ogden, and M. Tajik, J. Chem. Soc., Dalton Trans. 1986, 1587

${ }^{10}$ H. L. Krauss and K. Stark, Z. Naturforsch. Teil B 17, 1 (1962).

${ }^{11}$ H. F. Schaefer III, J. Mol. Struct. (Theochem) 76, 117 (1981).

${ }^{12}$ W. J. Pietro and W. J. Hehre, J. Comput. Chem. 4, 241 (1983).

${ }^{13}$ H. P. Lüthi, J. H. Ammeter, J. Almlöf, and K. Faegri, Jr., J. Chem. Phys. 77, 2002 (1982).

${ }^{14}$ J. Almlöf, K. Faegri, Jr., and B. E. R. Schilling, Chem. Phys. Lett. 106, 266 (1984)

${ }^{15}$ H. P. Lüthi, P. E. M. Siegbahn, J. Almlöf, K. Faegri, Jr., and A. Heiberg, Chem. Phys. Lett. 1, 111 (1984).

${ }^{16}$ T. E. Taylor and M. B. Hall, Chem. Phys. Lett. 114, 338 (1985).

${ }^{17}$ H. Nakai, Y. Ohmori, and H. Nakatsuji, J. Chem. Phys. 95, 8287 (1991).

${ }^{18}$ S. K. Kang, H. Tang, and T. A. Albright, J. Am. Chem. Soc. 115, 1971 (1993).

${ }^{19}$ A. W. Ehlers and G. Frenking, J. Am. Chem. Soc. 116, 1514 (1994).

${ }^{20}$ S. Jitsuhiro, H. Nakai, M. Hada, and H. Nakatsuji, J. Chem. Phys. 101, 1029 (1994)

${ }^{21}$ V. Jonas and W. Thiel, J. Chem. Phys. 102, 8474 (1995).

${ }^{22}$ W. J. Hehre, L. D. Burke, A. J. Shusterman, and W. J. Pietro, Experiments in Computational Organic Chemistry (Wavefunction, Inc., California, 1993).

${ }^{23}$ R. J. Deeth, J. Phys. Chem. 97, 11625 (1993).

${ }^{24}$ P. Hohenberg and W. Kohn, Phys. Rev. B 136, 864 (1964).

${ }^{25}$ W. Kohn and L. J. Sham, Phys. Rev. A 140, 1133 (1965).

${ }^{26}$ R. G. Parr and W. Yang, Density-Functional Theory of Atoms and Molecules (Oxford University Press, New York, 1989).

${ }^{27}$ R. O. Jones and O. Gunnarsson, Rev. Mod. Phys. 61, 689 (1989).

${ }^{28}$ Density Functional Methods in Chemistry, edited by J. K. Labanowski and J. Andzelm (Springer, New York, 1991).

${ }^{29}$ (a) T. Ziegler, Chem. Rev. 91, 651 (1991); (b) Can. J. Chem. 73, 743 (1995).

${ }^{30}$ T. Ziegler, Pure Appl. Chem. 28, 1271 (1991).

${ }^{31}$ B. Delley, J. Chem. Phys. 94, 7245 (1991).

${ }^{32}$ J. M. Seminario, M. C. Concha, and P. Politzer, Int. J. Quantum Chem. Symp. 25, 249 (1991)

${ }^{33}$ J. Andzelm and E. Wimmer, J. Chem. Phys. 96, 1280 (1992).

${ }^{34}$ N. C. Handy, P. E. Maslen, R. D. Amos, and J. S. Andrews, Chem. Phys. Lett. 197, 506 (1992).

${ }^{35}$ C. W. Murray, G. J. Laming, N. C. Handy, and R. D. Amos, Chem. Phys. Lett. 199, 551 (1992).

${ }^{36}$ P. M. W. Gill, B. G. Johnson, J. A. Pople, and M. J. Frisch, Int. J. Quantum Chem. Symp. 26, 319 (1992).

${ }^{37}$ K. Kim and K. D. Jordan, J. Phys. Chem. 98, 10089 (1994).

${ }^{38}$ M. Torrent, M. Duran, and M. Solà, Adv. Mol. Sim. (in press).

${ }^{39}$ (a) B. G. Johnson, P. M. W. Gill, and J. A. Pople, J. Chem. Phys. 97, 7846 (1992); (b) 98, $5612(1993)$ 
${ }^{40}$ C. Adamo and F. Lelj, J. Chem. Phys. 103, 10605 (1995).

${ }^{41}$ M. Solà, J. Mestres, R. Carbó, and M. Duran, J. Chem. Phys. 104, 636 (1996).

${ }^{42}$ C. Sosa, J. Andzelm, B. C. Elkin, E. Wimmer, K. D. Dobbs, and D. A. Dixon, J. Phys. Chem. 96, 6630 (1992).

${ }^{43}$ R. J. Gillespie, Chem. Soc. Rev. 1992, 59.

${ }^{44}$ M. J. Frisch, G. W. Trucks, M. Head-Gordon, P. M. W. Gill, M. W. Wong, J. B. Foresman, B. G. Johnson, H. B. Schlegel, M. A. Robb, E. S. Replogle, R. Gomperts, J. L. Andrés, K. Raghavachari, J. S. Binkley, C. González, R. L. Martin, D. J. Fox, D. J. DeFrees, J. Baker, J. J. P. Stewart, and J. A. Pople, Gaussian 92-DFT, Revision G.1 (Gaussian Inc., Pittsburgh PA, 1992).

${ }^{45}$ GAMESS-M. W. Schmidt, K. K. Baldridge, J. A. Boatz, S. T. Elbert, M. S. Gordon, J. J. Jensen, S. Koseki, N. Matsunaga, K. A. Nguyen, S. Su, T. L. Windus, M. Dupuis, J. A. Montgomery, J. Comput. Chem. 14, 1347 (1993).

${ }^{46}$ B. Delley, J. Chem. Phys. 92, 508 (1990). DMol, Biosym Technologies, Inc., San Diego, CA.

${ }^{47}$ Amsterdam Density Functional (ADF), Vrije Universiteit, De Boelelaan 1083, 1081 HV Amsterdam, The Netherlands, 1993.

${ }^{48}$ (a) J. C. Slater, Quantum Theory of Atomic Structure (McGraw-Hill, New York, 1960); (b) O. Gunnarson and I. Lundqvist, Phys. Rev. B 10, 1319 (1974).

${ }^{49}$ S. J. Vosko, M. Wilk, and M. Nusair, Can. J. Phys. 58, 1200 (1980).

${ }^{50}$ L. Hedin and B. I. Lundqvist, J. Phys. Chem. 4, 2064 (1971).

${ }^{51}$ (a) A. D. Becke, J. Chem. Phys. 84, 4524 (1986); (b) 88, 1053 (1988).

${ }^{52}$ A. D. Becke, J. Chem. Phys. 88, 2547 (1988).

${ }^{53}$ C. Lee, W. Yang, and R. G. Parr, Phys. Rev. B 37, 786 (1988).

${ }^{54}$ J. P. Perdew, Phys. Rev. B 33, 8822 (1986).

${ }^{55}$ (a) P. J. Hay and W. R. Wadt, J. Chem. Phys. 82, 270 (1985); (b) W. R. Wadt and P. J. Hay, ibid. 82, 284 (1985); (c) P. J. Hay and W. R. Wadt, ibid. 82, 299 (1985)

${ }^{56}$ (a) J. S. Binkley, J. A. Pople and W. J. Hehre, J. Am. Chem. Soc. 102, 939 (1980); (b) M. S. Gordon, J. S. Binkley, J. A. Pople, W. J. Pietro, and W. J. Hehre, ibid. 104, 2797 (1982); (c) W. J. Pietro, M. M. Francl, W. J. Hehre, D. J. DeFrees, J. A. Pople, and J. S. Binkley, ibid. 104, 5039 (1982).

${ }^{57}$ K. D. Dobbs and W. J. Hehre, J. Comput. Chem. 8, 861 (1987).

${ }^{58}$ A. J. H. Wachters, J. Chem. Phys. 52, 1033 (1970).

${ }^{59}$ (a) W. J. Hehre, R. Ditchfield, and J. A. Pople, J. Chem. Phys. 56, 2257 (1972); (b) P. C. Hariharan and J. A. Pople, Theor. Chim. Acta 28, 213 (1973); (c) M. S. Gordon, Chem. Phys. Lett. 76, 163 (1980).

${ }^{60}$ J. Krijn and E. J. Baerends, Fit Functions in the HFS-methods (Internal Report, Free University of Amsterdam, The Netherlands, 1984).

${ }^{61}$ (a) G. J. Snijders, E. J. Baerends, and P. Vernooijs, At. Nucl. Data Tables 26, 483 (1982); (b) P. Vernooijs, G. J. Snijders, and E. J. Baerends, Slater Type Basis Functions for the Whole Periodic Table (Internal Report, Vrije Universiteit Amsterdam, 1981).
${ }^{62}$ (a) E. J. Baerends, D. E. Ellis, and P. E. Ros, Chem. Phys. 2, 41 (1973);

(b) E. J. Baerends, Ph.D. Thesis, Vrije Universiteit Amsterdam, 1975.

${ }^{63}$ J. B. Foresman, M. Head-Gordon, and J. A. Pople, J. Phys. Chem. 96, 135 (1992).

${ }^{64}$ T. Ziegler, A. Rauk, and E. J. Baerends, J. Theor. Chim. Acta 43, 261 (1977).

${ }^{65}$ J. Mestres, ELECTRA, IQC, Girona, CAT, 1994.

${ }^{66}$ C. D. Garner and R. Mather, J. Chem. Soc., Chem. Commun. 1973, 633.

${ }^{67}$ R. J. French, L. Hedberg, K. Hedberg, G. L. Gard, and B. M. Johnson, Inorg. Chem. 22, 892 (1983).

${ }^{68}$ J. Wang, Z. Shi, R. J. Boyd, and C. A. Gonzalez, J. Phys. Chem. 98, 6988 (1994).

${ }^{69}$ J. Andzelm, E. Radzio, and D. R. Salahub, J. Comput. Chem. 6, 520 (1985).

${ }^{70}$ D. A. Dixon, J. Andzelm, G. Fitzgerald, E. Wimmer, and P. Jasien, Density Functional Methods in Chemistry, edited by J. Labanowski and J. W. Andzelm (Springer, New York, 1991).

${ }^{71}$ A. D. Becke, Phys. Rev. A 38, 3098 (1988).

${ }^{72}$ (a) M. Flock and M. Ramek, Int. J. Quantum Chem., Quantum Chem. Symp. 27, 331 (1993); (b) J. A. Pople, A. P. Scott, M. W. Wong, and L. Radom, Israel J. Chem. 33, 345 (1993); (c) R. S. Grev, C. L. Janssen, and H. F. Schaefer III, J. Chem. Phys. 95, 5128 (1991); (d) W. J. Hehre, L. Radom, P.v.R. Schleyer, and J. A. Pople, Ab Initio Molecular Orbital Theory (Wiley, New York, 1986).

${ }^{73} \mathrm{~K}$. Nakamoto, Infrared Spectra of Inorganic and Coordination Compounds, 2nd ed. (Wiley, New York, 1970).

${ }^{74}$ G. Rauhut and P. Pulay, J. Chem. Phys. 99, 3093 (1995).

${ }^{75}$ (a) I. R. Beattie, J. M. Brown, S. Firth, R. D. Gordon, T. R. Gilson, P. J. Jones, M. R. Levy, K. R. Millington, and S. Williams, J. Chem. Phys. Lett. 108, 138 (1984); (b) R. D. Gordon, I. R. Beattie, J. M. Brown, and S. Firth, J. Chem. Phys. 85, 2423 (1986).

${ }^{76}$ K. Yasuda and H. Nakatsuji, J. Chem. Phys. 99, 1945 (1993).

${ }^{77}$ J. P. Jasinski, S. L. Holt, J. H. Wood, and L. B. Asprey, J. Chem. Phys. 63, 757 (1975).

${ }^{78}$ J. B. Foresman, M. Head-Gordon, J. A. Pople, and M. J. Frisch, J. Phys. Chem. 96, 134 (1992).

${ }^{79}$ T. Shimanouchi, J. Phys. Chem. 6, 993 (1977).

${ }^{80}$ T. Ziegler, A. Rauk, and E. J. Baerends, J. Chem. Phys. 16, 290 (1976).

${ }^{81}$ V. Miskowski, H. B. Gray, and C. Ballhausen, J. Mol. Phys. 28, 729 (1974).

${ }^{82}$ R. G. Pearson, Acc. Chem. Res. 26, 250 (1993).

${ }^{83}$ I. R. Beattie, C. J. Marsden, and J. S. Ogden, J. Chem. Soc., Dalton Trans. 1980, 535.

${ }^{84}$ R. F. W. Bader, Atoms in Molecules-A Quantum Theory (Oxford University Press, Oxford, 1990).

${ }^{85}$ R. F. W. Bader, Chem. Rev. 91, 893 (1991). 